\title{
Primed picture naming within and across languages: An ERP investigation
}

\author{
Krysta Chauncey and Phillip J. Holcomb \\ Tufts University, Medford, Massachusetts \\ AND \\ JONATHAN GRAINGER \\ CNRS and Aix-Marseille University, Marseille, France
}

\begin{abstract}
In two experiments, while event-related potentials (ERPs) were recorded, participants named picture targets that were preceded by masked word primes that corresponded either to the name of the picture target or to an unrelated picture name. Experiment 1 showed significant priming effects in the ERP waveforms, free from articulator artifact, starting as early as $200 \mathrm{msec}$ post target onset. Possible loci of these priming effects were proposed within the framework of generic interactive activation models of word recognition and picture naming. These were grouped into three main components: object-specific structural representations, amodal semantic representations, and word-specific phonological and articulatory representations. Experiment 2 provided an initial test of the possible role of each of these components by comparing within-language repetition priming with priming from translation equivalents in bilingual participants. The early and widespread effects of noncognate translation primes in L1 on picture naming in L2 point to object-specific and amodal semantic representations as the principal loci of priming effects obtained with masked word primes and picture targets.
\end{abstract}

Over the past two decades, masked priming has been applied extensively in the study of the basic mechanisms involved in letter and word perception (Forster \& Davis, 1984; Jacobs \& Grainger, 1991; Segui \& Grainger, 1990). Forster (1998) summarized the advantages of the masked priming technique as compared with the more conventional priming techniques that use longer prime durations and with the standard across-item comparisons that do not involve priming. Priming manipulations allow the experimenter to control for many of the confounds present in direct comparisons of different categories of stimuli, and masked priming limits the use of strategies that might develop when primes are visible and participants are aware of the priming manipulation.

Although the masked priming technique has been less extensively applied in related fields of research (e.g., object and face recognition), the methodological advantages are the same and deserve to be more fully exploited. Furthermore, the combination of different types of stimuli in the prime and target position (cross-domain priming; e.g., with words and pictures) opens up a vast perspective for research exploring the precise nature of the information processing that subtends the recognition of a particular type of stimulus (within-domain processing). In one of the first studies to apply masked priming across domains, Ferrand, Grainger, and Segui (1994) used word stimuli as primes and pictures of objects as targets in a picturenaming study (for a more recent application of this para- digm, see Finkbeiner \& Caramazza, 2006). Ferrand et al. found robust facilitation from primes that were the object's name, as compared with that from different-name primes, and this facilitatory priming was of the same magnitude for target objects with either low- or high-frequency names. These results therefore suggest that picture naming recruits representations that are activated by briefly presented, pattern-masked word stimuli. Among the possible candidates for such cross-domain interactions are amodal semantic representations and phonological representations that correspond to the name of the target picture.

Since the picture-naming task is one of the most popular behavioral measures of single-word production (Levelt, Roelofs, \& Meyer, 1999), the results of Ferrand et al.'s (1994) study point to a potential application of this methodology in the study of language production. The present study builds on Ferrand et al.'s pioneering work in combining masked priming and picture naming and adds the recording of event-related potentials (ERPs). Previous studies using ERPs in the masked priming paradigm have demonstrated that this technique can provide valuable additional information about the relative timing of the underlying processes (e.g., Holcomb \& Grainger, 2006).

\section{ERPs and Masked Priming}

Recent research has begun to combine masked priming with ERP recordings using printed word stimuli (Holcomb \& Grainger, 2006, 2007; Kiyonaga, Grainger, Midgley, \& 
Holcomb, 2007), isolated letters (Petit, Midgley, Holcomb, \& Grainger, 2006), pictures of objects (Eddy, Schmid, \& Holcomb, 2006), and faces (Henson, Mouchlianitis, Matthews, \& Kouider, 2008). All of these studies have shown priming effects in the classic N400 time window, probably linked to the semantic processing of each of these different types of stimuli. These studies have also highlighted a number of earlier ERP components that are likely related to early visual and later form-based processing. For example, the word priming experiments of Holcomb and Grainger $(2006,2007)$ revealed a component peaking at around $250 \mathrm{msec}$ post target onset that was sensitive to their priming manipulation and was thought to reflect processing involved in mapping prelexical form representations onto whole-word form representations.

Nearly all of the prior research using ERPs to investigate speech production has avoided using explicit production tasks such as picture naming. Instead participants would be requested to covertly name picture targets, with a manual response being the main task, or to delay their naming response until after the manual response. The manual response task could require classifying the picture as belonging to a given semantic category or not (semantic task) or could require responding on the basis of some phonological property of the picture name (phonological task). In three studies using this general approach (Rodriguez-Fornells, Schmitt, Kutas, \& Münte, 2002; Schmitt, Münte, \& Kutas, 2000; van Turennout, Hagoort, \& Brown, 1997), the ERP data (N200 and LRP latencies) showed evidence for early semantic processing of picture stimuli followed by phonological encoding, as predicted. However, the use of ERPs generated by a manual response is a rather indirect way of investigating basic processes in picture naming. Recent research has nevertheless demonstrated the feasibility of combining ERPs with a normal picture-naming procedure (Christoffels, Firk, \& Schiller, 2007; Verhoef, Roelofs, $\&$ Chwilla, 2009). The present study provides a further test of the utility of combining picture naming and ERP recordings while adding a masked priming component to this general procedure.

\section{The Present Study}

The two experiments reported here extend previous masked priming studies using ERPs (e.g., Eddy et al., 2006; Holcomb \& Grainger, 2006; Midgley, Holcomb, $\&$ Grainger, 2009) to a cross-domain situation with word primes and picture targets. As is commonly the case in behavioral research, participants had to say aloud the name of the picture target (i.e., picture naming). The primary goal of the first experiment was to test the feasibility of using an immediate naming task in an ERP paradigm. As mentioned above, previous studies using naming with ERPs have generally used either covert naming or delayed naming (with participants naming the word after a delay of about $1 \mathrm{sec}$ ) because ERPs are easily distorted by any movement of muscles in the head and face area (Koester \& Schiller, 2008; Tremblay, Schiller, \& Gracco, 2008). This makes it almost impossible to obtain clean, artifactfree data while speech is occurring. However, average response times (RTs) during picture naming tend to be relatively long, especially as compared with those during word naming (see, e.g., Ferrand et al., 1994), suggesting that ERP measurement up to the point of articulation might be obtained prior to the onset of articulator artifact.

In the first experiment, we manipulated the relationship between prime words and target pictures, so that primes could be either the name of the upcoming picture or the name of a totally unrelated picture (taken from another related trial). ERPs were time locked to target-picture onset, and naming responses to target pictures were monitored. Experiment 1 therefore provides an initial investigation of primed picture naming with ERP recordings. In the Discussion section of Experiment 1, we provide a preliminary attempt at interpreting the different ERP components found to be modulated by priming. This interpretation is presented within the framework of a generic interactive activation account of visual word recognition (McClelland \& Rumelhart, 1981) and picture naming (Dell, 1986). Experiment 2 then provides a first test of this proposal using bilingual participants tested with primes presented in either L1 or L2 and pictures named in either L1 or L2. Testing bilingual participants will allow us to further separate the contribution of form and meaning representations in driving repetition priming effects by contrasting within-language repetition and between-language translation priming with noncognate translations (i.e., translation equivalents with minimal form overlap).

\section{EXPERIMENT 1}

\section{Method}

Participants. Twenty-four participants (12 female; age range $=$ 18-22 years, $M=19.7$ ) were recruited from Tufts University and compensated for their time. All were right-handed native speakers of English with no exposure to languages other than English before the age of seven.

Design and Stimuli. The stimuli for the study consisted of prime-target pairs of words (primes) and pictures of common objects (targets). Targets were single-object color images selected on the basis of a picture rating study in which 24 participants named a pool of 300 pictures. The most common single-word name for each object was selected and formed the name used as the prime in the present experiment. Fifty critical trials contained a target picture preceded by a prime word that was the name of the object depicted (related condition), and another 50 trials contained unrelated prime words and target objects (unrelated condition). The 100 critical trials were randomly mixed with 200 filler trials. The filler trials consisted of unrelated prime words and picture targets. Each prime and target item was rotated through the related and unrelated conditions across participants. This scheme ensured that all items would occur in all conditions an equal number of times, but that no participant would see any item more than once.

Procedure. After providing informed consent, participants were fitted with an electrode cap and seated in a comfortable armchair in a sound-attenuated room with dimmed lighting. They then completed the training session before performing the main experiment. Each trial of the main experiment consisted of a 500-msec fixation cross that was replaced in rapid succession by a 200 -msec forwardpatterned mask, a $70-\mathrm{msec}^{1}$ prime word, a backward mask (average duration of $50 \mathrm{msec}$ ), a 200 -msec target picture, a blank-screen interval (at least $900 \mathrm{msec}$, but no longer than the verbal naming response), and a 1,000-msec period for blinking (see Figure 1). Participants were instructed to say aloud the name of the object shown 


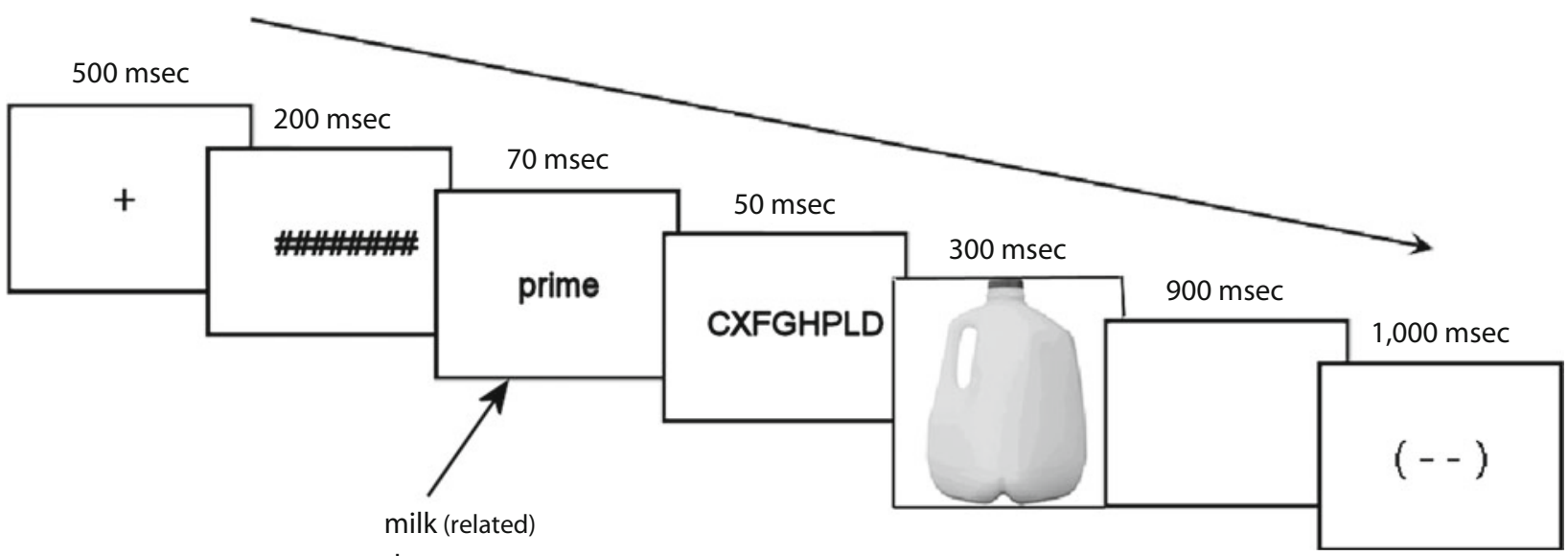

door (unrelated)

Figure 1. A typical trial in Experiment 1.

in the picture (overt picture naming) as soon as they knew it. Accuracy was stressed before speed in this experiment, since we did not want to encourage rapid articulatory onset.

Training session. In many picture-naming studies, a training phase is used in order to increase name agreement across participants and encourage fluent responding. In the present study, participants were trained by viewing the object name, followed by a picture of the item, and followed by the object name again. Participants were also asked to say the name of the pictured object aloud. The picture names were those selected on the basis of the picture rating study described above. Both pictures and words were formatted to reduce perceptual overlap between the training phase and the experimental phase as much as possible: Pictures appeared in black and white in the training phase and in full color during the experimental phase; words were displayed in uppercase Times New Roman letters in the training phase and in lowercase Arial letters in the experimental phase.

ERP procedures. Electroencephalograms (EEGs) were collected using 32-channel caps (Electro-cap International), in which tin electrodes were arranged using the standard International 10-20 system (see Figure 2). One electrode was placed beside the left eye and one below the right eye to monitor for blinks and saccades. Two electrodes were placed behind the two ears on the mastoid bone: The left mastoid site (A1) was used as an online reference for all electrodes, and the right mastoid site (A2) was recorded to evaluate differential mastoid activity (there was none that differentially affected any of the conditions). Impedance was measured at less than $2 \mathrm{k} \Omega$ for the scalp and mastoid electrode sites and at less than $10 \mathrm{k} \Omega$ for both eye channels. The EEG was amplified using an SA Bioamplifier (SA Instruments, San Diego) operating on a band pass of 0.01-40 Hz. The digitizing computer continuously sampled the EEG at a rate of $200 \mathrm{~Hz}$, while the stimulus computer simultaneously issued stimuli to the participant's monitor.

Data analysis. ERP data from a representative subarray of the full 28-channel scalp montage was used for analysis. This included 15 sites extending from the front to the back of the head, as well as over left-hemisphere, center, and right-hemisphere locations (see Figure 2). We have used this approach to ERP data analysis successfully in a number of previous studies (e.g., Grainger, Kiyonaga, \& Holcomb, 2006) and find it to be the best compromise between simplicity of design (a single ANOVA can be used in each analysis epoch) and full description of the distribution of effects. All data were analyzed in a multifactor repeated measures design with factors of prime-target relatedness (related or unrelated) and additional scalp distribution factors of electrode laterality (left, center, or right) and anterior-to-posterior electrode placement (FP, front polar; F, frontal; C, central; $\mathrm{P}$, parietal; or $\mathrm{O}$, occipital). All repeated mea- sures used the Greenhouse-Geisser (1959) correction. All analyses yielding significant effects $(p<.05)$ are reported, with the exception of main effects of distributional variables (i.e., laterality and anterior-posterior). The dependent measures in our ERP analyses were the mean amplitude measurements in three consecutive time windows: $200-300 \mathrm{msec}, 300-500 \mathrm{msec}$, and 500-700 msec. In our previous work, these windows were used to assess activity in the $\mathrm{N} 250 / \mathrm{N} 300$, the N400, and the post-N400 epochs (e.g., Eddy et al., 2006; Holcomb \& Grainger, 2006). Finally, to determine whether the activity in the three measurement windows was due to different configurations of neural generators (i.e., different ERP components), we also ran a distributional ANOVA on priming effects. The data for this analysis were calculated from difference waves (unrelated - related) and contrasted the three temporal measurement epochs (200-300 msec vs. 300-500 msec vs. 500-700 msec). The distribution analysis was performed on raw mean amplitude values, as well as on amplitudes normalized separately within each

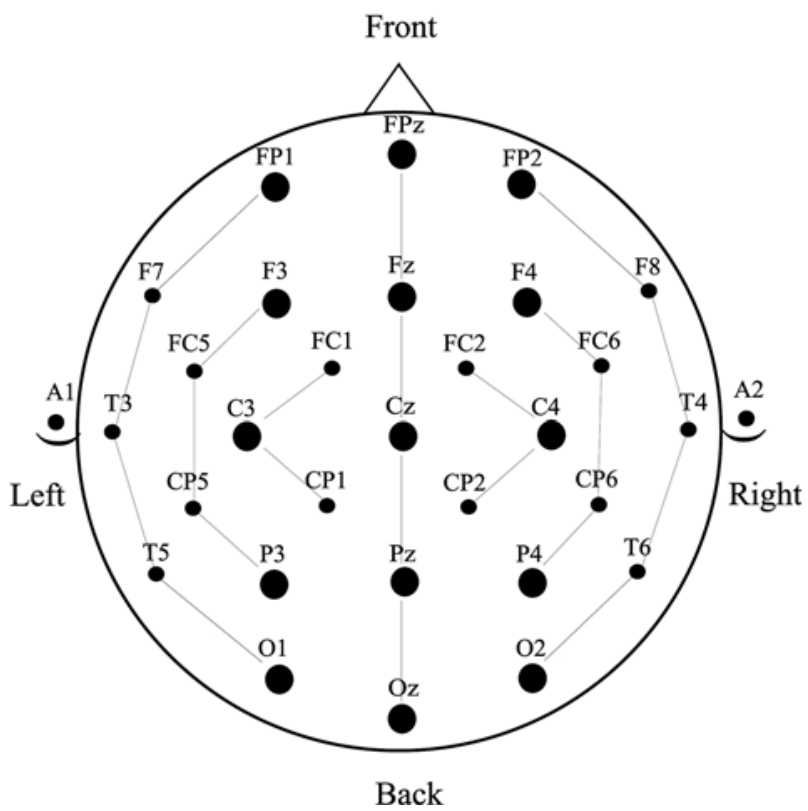

Figure 2. Electrode montage (analysis sites are indicated by larger dots). 
time window (Rösler, Pütz, Friederici, \& Hahne, 1993). Evidence for different components is supported by significant interactions between scalp-site variables (anterior-posterior and/or laterality) and measurement windows (epochs). For behavioral data, we analyzed the latency of picture naming on correct trials and the percentage of naming errors.

\section{Results}

ERP results. The ERPs time-locked to picture targets from the 15 representative scalp sites used in the analyses reported below are plotted in Figure 3. The graphs are terminated at $700 \mathrm{msec}$ because, shortly after this point, ar-
FP1

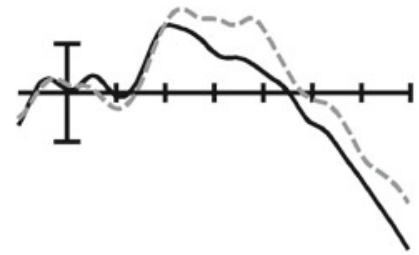

F3

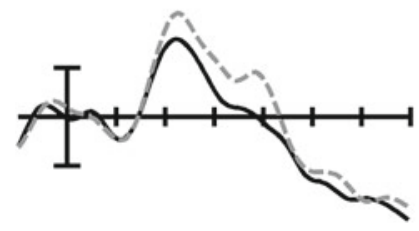

C3

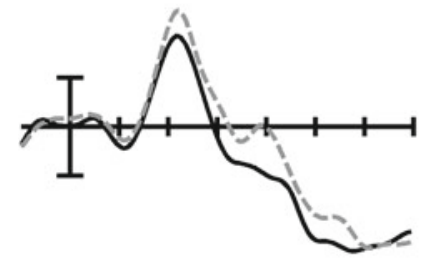

P3

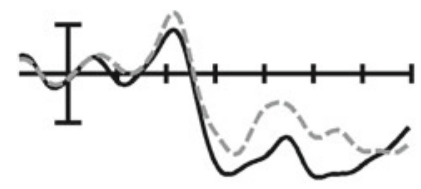

01
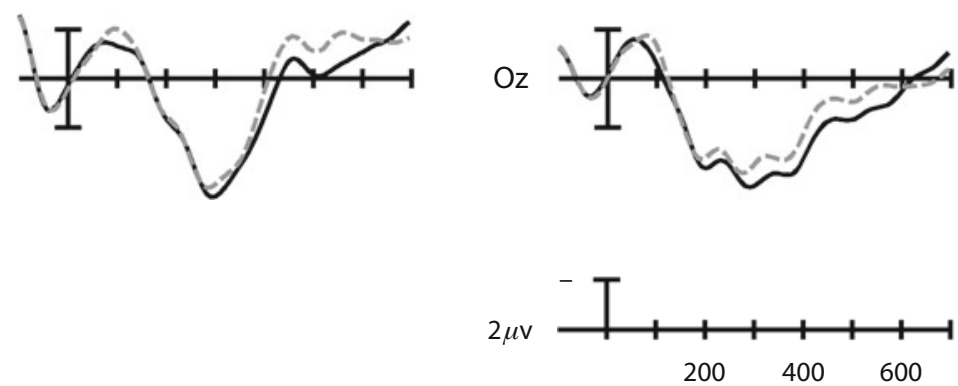

$\mathrm{Fz}$

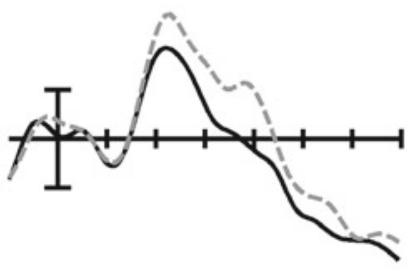

Cz

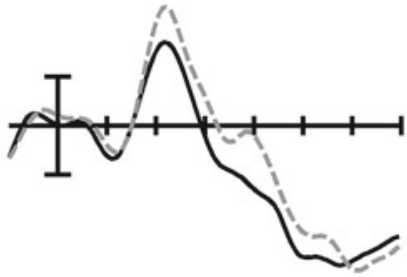

$\mathrm{Pz}$

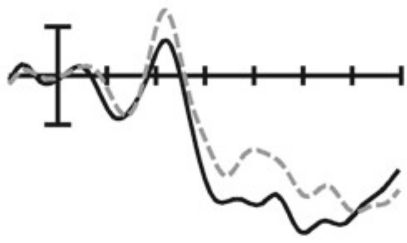

$\mathrm{Oz}$

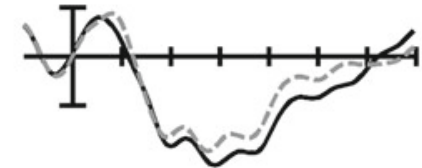

FP2

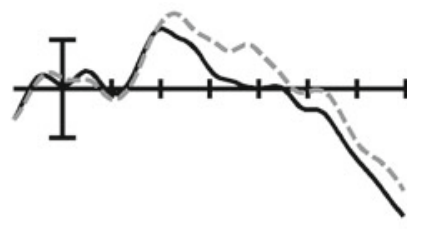

P4

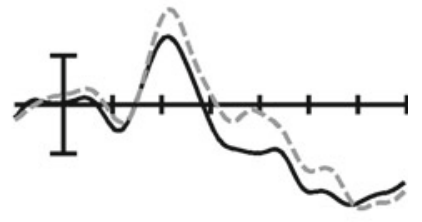

F4

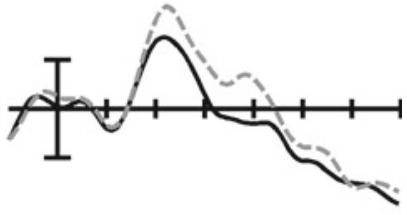

C4

$\mathrm{O} 2$

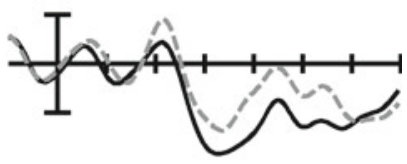

Figure 3. ERPs from 15 scalp sites time-locked to target pictures in a picture-naming task when the preceding prime word was the name of the pictured object (related) or was the name of some other object (unrelated). Target onset is marked by the vertical calibrating bar, and each tick mark on the $x$-axis represents 100 msec. 
tifacts from the earliest target naming responses started to contaminate the ERPs. It is important to point out that, in previous ERP masked priming studies, all of the reported effects occurred prior to $700 \mathrm{msec}$, so it is likely that little of importance is being missed here. The voltage maps resulting from subtracting the related target ERPs from the unrelated target ERPs (i.e., the priming effect) computed from all 28 scalp sites for each of the three analysis epoch ranges are plotted in Figure 7A.

In the first epoch (200- to 300-msec window), target pictures were significantly more negative-going when the immediately preceding prime word was unrelated to the target than when the prime word was the name of the picture $[F(1,23)=10.26, p=.0039]$. This trend was more apparent at midline sites $[F(2,46)=3.8, p=.0298]$ (see Figure 3).

In the second epoch (the 300- to 500-msec window), there were main effects of relatedness $[F(1,23)=15.67$, $p=.0006]$, with unrelated targets producing greater negativity than related targets, but this effect differed across the scalp, being larger at midline sites toward the front of the head $[F(8,184)=3.05, p=.003]$.

In the final epoch (the 500- to 700-msec window), there was again a relatedness $\times$ anterior-posterior $\times$ laterality interaction $[F(8,184)=2.38, p<.0181]$, which indicated a more anterior priming effect (see Figures 3 and 7A).

Distributional analyses. In contrasts of the priming effect (unrelated - related) across the three measurement windows, there were significant anterior-posterior $\times$ laterality $X$ epoch interactions both for the raw mean amplitude values $[F(16,368)=2.53, p=.001]$ and for those normalized separately for each measurement window $[F(16,368)=$ $2.36, p=.0024]$. Follow-up analyses contrasting the early and middle windows and middle and late windows revealed this same significant interaction (all $p \mathrm{~s}<.05$ ).

Behavioral results. Incorrect responses, false starts, and hesitations were counted as errors. An ANOVA performed on participants' naming accuracy showed a main effect of relatedness $[F(1,23)=7.283, p=.013]$. Pictures that were unrelated to the preceding prime word were named less accurately than were pictures following related primes. A similar pattern was obtained with naming latency (for correct responses); pictures related to the prior word were named significantly faster than were pictures following unrelated prime words $[F(1,19)=49.159$, $p<.001$ ] (see Table 1).

\section{Discussion}

The results of Experiment 1 revealed robust crossdomain priming starting as early as $200 \mathrm{msec}$, with masked prime words of $70 \mathrm{msec}$ in duration rapidly followed by target objects. This priming effect continued through the

Table 1

Behavioral Data for Experiment 1

\begin{tabular}{lcccc}
\hline & \multicolumn{2}{c}{ Accuracy $(\%)$} & \multicolumn{2}{c}{ Naming RT } \\
\cline { 2 - 5 } & $M$ & $S D$ & $M$ & $S D$ \\
\hline Related & 92.08 & 7.66 & 1,179 & 145.95 \\
Unrelated & 88.33 & 6.09 & 1,305 & 110.99 \\
\hline
\end{tabular}

following two epochs, lasting at least $700 \mathrm{msec}$. Importantly, there was little evidence of artifact due to the overt naming response prior to $700 \mathrm{msec}$. In the time window up to $700 \mathrm{msec}$ post target onset, there was evidence for three distinct components, each affected by our priming manipulation. This conclusion is supported by examination of the ERPs and scalp maps (Figures 3 and 7A, respectively), as well as by distributional analyses, which contrasted priming effects (from difference waves) across the three time epochs. There were significant differences in the distribution of priming as a function of time epoch. The first of these components, which was more negative for unrelated targets, peaked just after $200 \mathrm{msec}$ post target onset and had an anterior distribution that was slightly larger over the right hemisphere. The second, which was also more negative for unrelated targets, peaked around $400 \mathrm{msec}$ post target onset and had a more central distribution. The final component, also more negative for unrelated targets, peaked around 550 msec post target onset and was widely distributed and slightly larger over the left hemisphere. The results of this first experiment suggest that picture naming and masked priming can be successfully combined with ERP recordings and used to explore the time course of word-picture interactions. These wordpicture interactions should help to define the nature of the component processes involved in naming pictures of objects and to specify their relative time course. Figure 4 provides a tentative outline of these component processes and their possible interactions.

The visual word recognition part of Figure 4 is taken from the bimodal interactive activation (BIA) model (Diependaele, Ziegler, \& Grainger, in press; Grainger, Diependaele, Spinelli, Ferrand, \& Farioli, 2003; Grainger \& Holcomb, 2009; Grainger \& Ziegler, 2007; Holcomb \& Grainger, 2007). Visual features map onto prelexical orthographic representations (not shown), which then map onto whole-word orthographic representations ( $\mathrm{O}$ words) along the direct pathway to semantics and onto wholeword phonological representations ( $\mathrm{P}$ words). (For the sake of simplicity, the prelexical mapping of orthography to phonology in the BIA model is not shown.) With regard to picture stimuli, visual features are extracted from picture stimuli and send activation on to higher-order visual representations that in turn map onto structural representations of objects (obj-reps), which then map onto semantics (e.g., Biederman, 1987). Following a now-standard account of picture naming, semantic activation leads to activation in whole-word phonological forms or lexemes (the picture name), and from there onto phonological segments, which in turn spread activation onto articulatory output representations. In order to keep matters as simple as possible, the process of grammatical encoding and the hypothesized role of lemma representations in certain models of speech production will not be discussed here (for a similar approach, see Finkbeiner, Gollan, \& Caramazza, 2006; Knobel, Finkbeiner, \& Caramazza, 2008).

Within the theoretical framework outlined in Figure 4, there are at least five possible sources of the effects of word primes on picture naming seen in the ERP waveforms of Experiment 1: (1) Structural representations of 


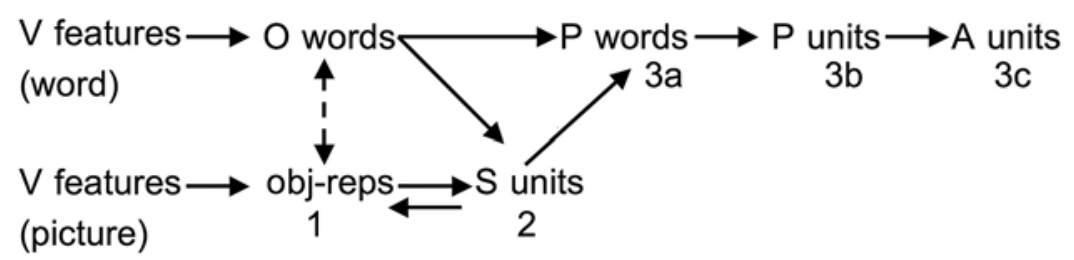

Figure 4. Component processes in visual word recognition and picture naming and their possible interactions in the adaptation of the bimodal interactive activation model of word recognition to the case of word and picture processing. Picture naming minimally requires activation of a structural representation of the to-be-named object (obj-reps), followed by semantic activation ( $S$ units), and followed by lexical phonology ( $P$ words), phonological segments ( $P$ units), and articulatory output codes (A units).

objects (obj-reps) that are activated by word primes via feedback from semantics (S units), or possibly directly by word representations (the dotted line in Figure 4); (2) semantic representations (S units) shared by word and picture stimuli (under the assumption that picture naming necessarily involves activation of semantics); (3a) lexical phonological representations (P words) involved in picture naming and activated by word primes; $(3 \mathrm{~b})$ phonological segments ( $\mathrm{P}$ units) involved in picture naming and activated by word primes; and (3c) articulatory output representations (A units) required for speech output and possibly activated by word primes.

In the analysis above, the possible loci have been simplified by regrouping the last three components into a single "phonological/articulatory" component. This simplification gives three main sources for our priming effects: object-specific form representations, amodal semantic representations, and word-specific (phonological/ articulatory) representations. We would tentatively associate the earliest effects seen in Experiment 1 (the priming effect just after $200 \mathrm{msec}$ post target onset) as reflecting preactivation of structural representations of pictures by word primes. This effect may correspond to a component seen in prior research, in which both primes and targets were picture stimuli, the N300 (Eddy et al., 2006). The fact that prime exposures were slightly longer than in Eddy et al.'s study might explain the earlier onset of this effect and the broader scalp distribution seen in Experiment 1. Within the framework of this tentative interpretation, the second priming effect (seen between 300 and $500 \mathrm{msec}$ ) would be on the N400 component and would reflect activation in semantic representations shared by word and picture stimuli. Here, related prime stimuli are thought to facilitate the mapping from semantic representations onto phonological word forms. Semantic effects can logically only follow effects tied to activation of structural object representations. Finally, the third priming effect seen in the 500 - to $700-\mathrm{msec}$ time window would be driven by phonological and/or articulatory representations required to produce the picture name.

Experiment 2 will allow us to test the possible role of word-specific phonological/articulatory representations in the priming effects found in Experiment 1. When we prime picture targets with their translation equivalents, the role of structural and semantic representations (1 and 2) remains intact, whereas the role of phonological and ar- ticulatory representations (3) is removed, since these will now differ across prime and target. In a similar vein, Experiment 2 will allow us to test an alternative interpretation of the early priming effect, seen in Experiment 1 as reflecting the detection of a mismatch between the word prime and the picture name.

\section{EXPERIMENT 2}

In this experiment, bilingual participants were presented with pictures of common objects (e.g., a truck) and were instructed to name them in their L1 (English; Experiment 2A) or their L2 (French; Experiment 2B). Following the procedure of Experiment 1, pictures were preceded by a brief presentation of a prime word $(70 \mathrm{msec})$ that was pattern masked by both forward- (a row of hash marks) and backward- (a row of consonant strings) masking stimuli. In each subexperiment, $50 \%$ of the prime words were in English (L1), and 50\% were in French (L2). Primes were either the name (in English or French) of the object in the following target picture (related) or were the name (in English or French) of a different, unpresented picture (unrelated). When primes were in the nontarget language, related primes were noncognate translations of the picture name (i.e., translation equivalents with minimal form overlap). On the basis of our interpretation of the priming effects found in Experiment 1, we expect to see a similar pattern of effects for within-language repetition priming and across-language translation priming up to and including the N400 time window. The only factor that should modify priming in these time windows is the relative speed of processing of L1 and L2 prime words. On the other hand, any word-specific priming (phonological and/or articulatory) should be affected by whether or not the prime word is in the same language as that used to name the picture.

\section{Method}

Participants. Sixteen university students (15 female) with an average age of 20 years (range $=18-22$ ) participated in Experiments $2 \mathrm{~A}$ and 2B. All were right-handed native speakers of English who were learning French as a second language. They all had normal or corrected-to-normal vision and no history of neurological insult or language disability. Participants' proficiency in L2 (French) was assessed by three measures: (1) a post-ERP-session translation task; (2) a language proficiency questionnaire that asked participants to evaluate their own skill at speaking, reading, writing, and understand- 
ing both L1 and L2, relative to their peers; and (3) a questionnaire that assessed type, duration, and recency of participants' language exposure. Participants had an average of 4.8 university-level French courses and an average of 5.6 months of immersive exposure to French; none had significant exposure to French prior to high school instruction. After the ERP experiment, participants were asked to translate all of the prime words from English to French. Their mean percentage correct was 78.2. Ratings of competence in English and French can be found in Table 2, where a 7 represents perfect competence and a 0 represents no competence. Comparisons between L1 and L2 were significantly different at the level of $p<.001$.

Design and Stimuli. The stimuli for this study consisted of word-picture pairs. Pictures were to be named in either English (L1) or French (L2) in two separate blocks (analyzed separately). A prime could be either a word from the same language as the target-naming task or a word from the other language, and could be either a related word (within-language repetition or noncognate translation) or the name of an unrelated object from another trial (see Table 3; note that related trials could be either within-language repetition primes or between-language translation primes as a function of their combination with the response language). Four experimental lists were created for each language's naming block (English, Experiment 2A; French, Experiment $2 \mathrm{~B}$ ), so that each individual word and picture appeared in each possible trial type in an equal number of participants and no word or picture appeared more than once in the same language block for any individual participant. There were 50 items per condition in each list. Pictures were taken from the same cohort as those used in Experiment 1. Prime words for a given picture in the two languages were range-matched as closely as possible on length, frequency, and concreteness, and individual primes were chosen to avoid diacritics, cognates, and faux amis. Each trial consisted of a 200 -msec forwardpatterned mask and was followed by a 70-msec presentation of the prime. The prime was immediately followed by a backward mask with a mean duration of $50 \mathrm{msec}$, a $300-\mathrm{msec}$ presentation of the target object, and a 2,900-msec intertrial interval. The intertrial interval consisted of $900 \mathrm{msec}$ of black space and a 2,000-msec blink stimulus (signaling that it was permissible to blink).

Procedure. This was the same as in Experiment 1, with the exception that the training sequence was repeated until participants felt they could comfortably name most objects without excessive delay. This was to ensure accurate picture naming in L2. Participants averaged two passes through the training sequence. The experiment was divided into two blocks, with all pictures named in English in one block and in French in the other block. Prime-word language varied from trial to trial within each block. The training sequence was conducted in L1 just prior to the English picture-naming ERP experiment (2A) and in L2 just prior to the French picture-naming ERP experiment (2B). During the experimental phase, participants were asked to name the objects pictured on a computer in their L1 (English) in Experiment 2A or their L2 (French) in Experiment 2B. Half of the participants were tested in their L1 and then in their L2, and the other half were tested in the opposite order.

Data analysis. All of the data were analyzed in a multifactor repeated measures design that included factors of prime language (L1, English; L2, French) and prime-target relatedness (related or unrelated). The results of each subexperiment were analyzed separately. As in Experiment 1, additional distributional factors of electrode laterality (left, center, or right) and anterior-to-posterior electrode placement (FP, F, C, P, or O) were included in the analyses of ERP data. When there were significant interactions between prime

Table 2

Participants' Self-Ratings of Their Reading, Speaking, and Oral Comprehension Skills in L1 and L2

\begin{tabular}{lccc}
\hline & Reading & Speaking & Comprehension \\
\hline English (L1) & 7 & 7 & 7 \\
French (L2) & 4.97 & 5.23 & 5.17 \\
\hline
\end{tabular}

Table 3 An Overview of Trial Types in Experiment 2

\begin{tabular}{lccc}
\hline \multicolumn{1}{c}{ Type } & Prime & Target & Spoken Response \\
\hline English & & & \\
$\quad$ Related & milk & & \\
Unrelated & drum & & "milk" (L1, Experiment 2A) \\
French & lait & "lait" (L2, Experiment 2B) \\
$\quad \begin{array}{l}\text { Related } \\
\text { Unrelated }\end{array}$ & tambour & & \\
\hline
\end{tabular}

language and prime-target relatedness, we followed the omnibus ANOVA up with separate analyses for each prime language (i.e., one for targets with English primes and one for targets with French primes). The same measurement windows used in Experiment 1 were used in Experiment 2 (i.e., 200-300 msec, 300-500 msec, and $500-700 \mathrm{msec}$ ). In a separate set of analyses, wme also directly compared the ERPs from trials with target pictures preceded by unrelated primes in the same language as the naming task (no-switch trials) with those from trials with target pictures preceded by unrelated primes in the other language (language-switch trials). For behavioral data, we analyzed the percentage of naming errors and the latency of picture naming on correct trials.

\section{Results: Experiment 2A}

ERP results. The ERPs from 15 representative scalp sites time-locked to target picture onset are plotted in Figures 5 and 6. Figure 5 shows ERPs time-locked to target pictures preceded by English prime words that are either unrelated to the target picture (L1-L1-unrelated) or are the picture name in English (L1-L1-related). Figure 6 shows ERPs time-locked to the same target pictures preceded by either unrelated French prime words (L2-L1-unrelated) or the picture name in French (L2-L1-related). The voltage maps resulting from subtracting the related-target ERPs from the unrelated-target ERPs in the L1-L1 (top) and L2-L1 (bottom) conditions are plotted in Figure 7B.

In the 200- to 300-msec window, the omnibus ANOVA revealed a significant prime language $\times$ relatedness $\times$ laterality interaction $[F(2,30)=3.94, p=.03]$. To better understand this interaction, we ran separate followup analyses on the English and French prime conditions. These analyses revealed that target pictures following English prime words were significantly more negativegoing when the prime word was unrelated to the target picture than when the prime word was the name of the picture. This trend was especially apparent at central and right-hemisphere sites $[F(2,30)=3.79, p=.034]$ (see Figure 5). There were no comparable priming effects for target pictures following French primes (all $p \mathrm{~s}>.6$ ) (see Figure 6).

In the 300- to 500-msec window, the omnibus ANOVA revealed robust priming effects $[F(1,15)=31.83, p<$ $.0001]$, but also indicated that priming was modulated by prime language $[F(1,15)=13.51, p=.0022]$ (see Figures 5 and 6). Again, separate follow-up analyses were run to decompose this interaction. For English primes, there were main effects of relatedness $[F(1,15)=34.65, p<$ $.0001]$, with unrelated targets producing greater negativity than related targets, but this effect differed across the scalp, being larger at central and right-hemisphere sites toward the front of the head $[F(8,120)=4.41, p=.0001]$. 

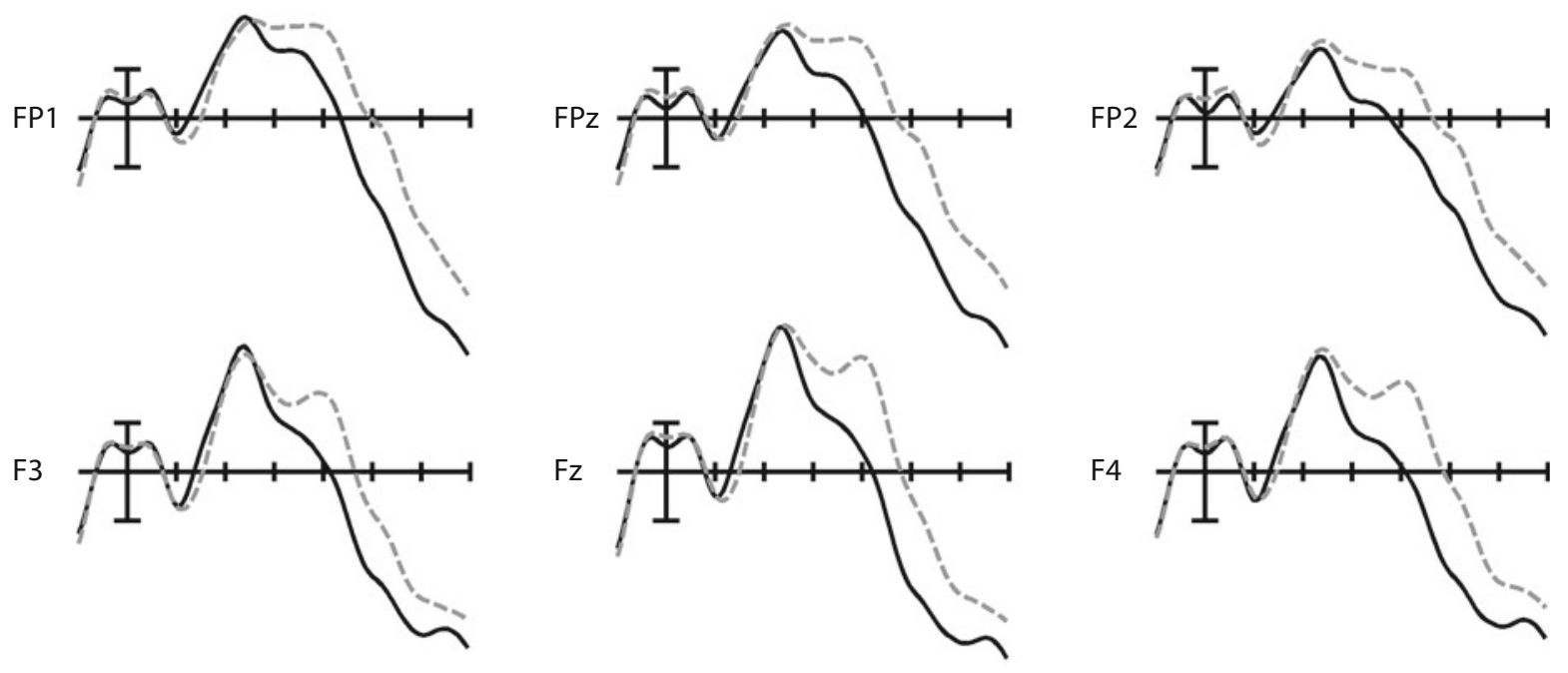

F3

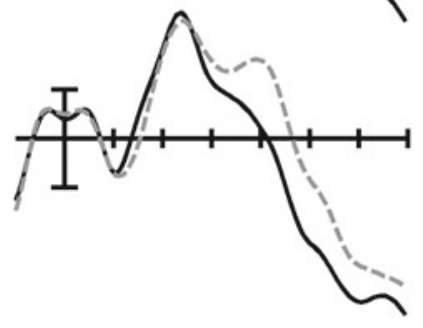

C3

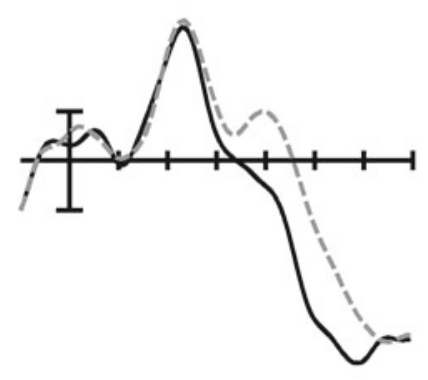

P3

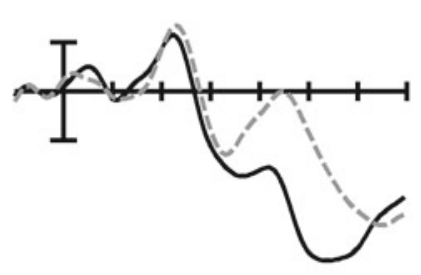

01

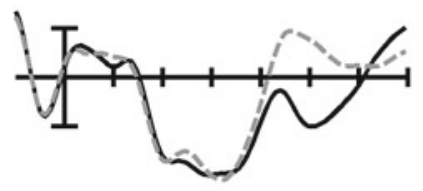

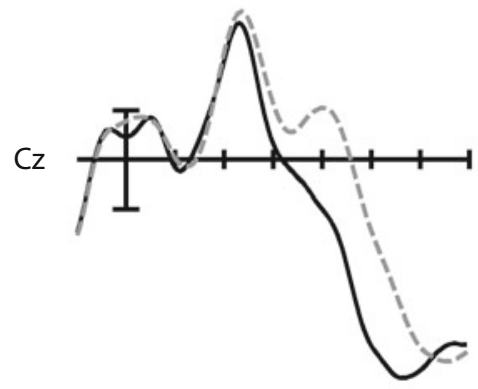

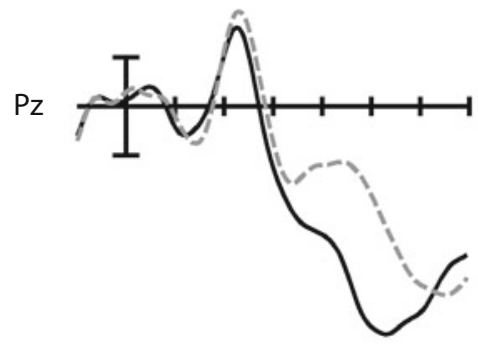

$\mathrm{Oz}$

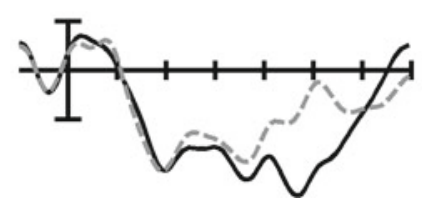

$2 \mu \mathrm{v}$

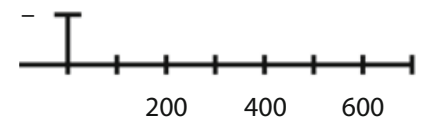

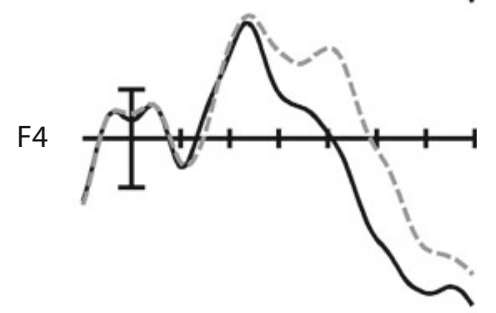

C4

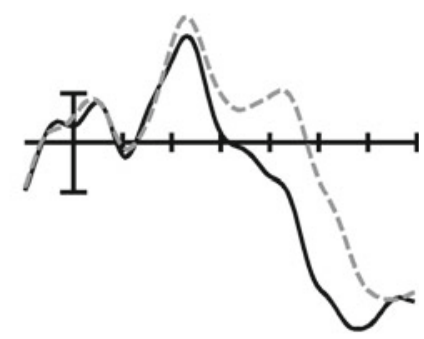

P4

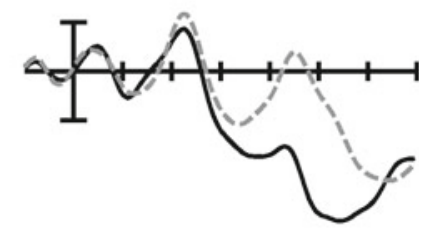

$\mathrm{O} 2$

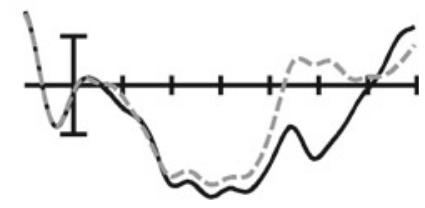

Related

Unrelated

Figure 5. ERPs from 15 scalp sites time-locked to target pictures in the English (L1) picture-naming block with English (L1) prime words. Target onset is marked by the vertical calibrating bar, and each tick mark on the $x$-axis represents 100 msec.

For French primes, there was a smaller main effect of relatedness $[F(1,15)=7.45, p=.0155]$ that did not differ significantly across the scalp.

In the 500- to 700-msec epoch, there were again relatedness effects in the omnibus ANOVA that differed as a function of prime language $[F(1,15)=10.60, p=.0053]$.
Separate follow-up analyses showed a robust relatedness effect for target pictures following English prime words, especially at central and right-hemisphere, more-anterior sites $[F(8,120)=4.99, p<.0001]$. There were no significant priming effects to target pictures following French primes in this epoch (all $p \mathrm{~s}>.35$ ). 
FP1

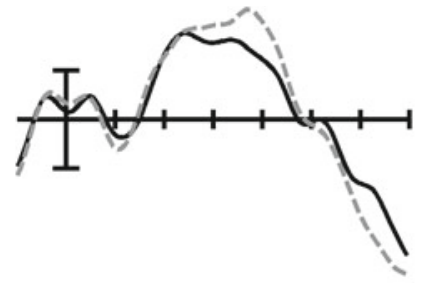

F3

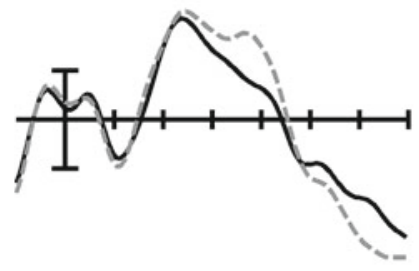

C3

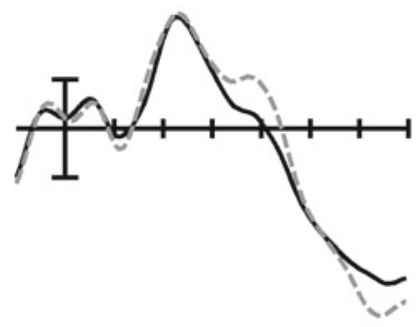

P3

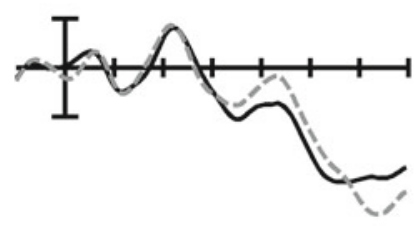

01

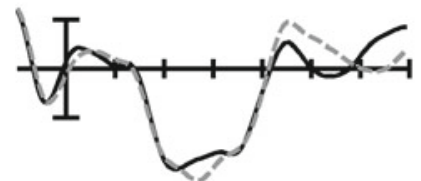

$\mathrm{FPz}$

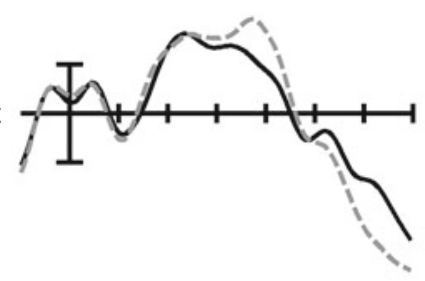

Fz

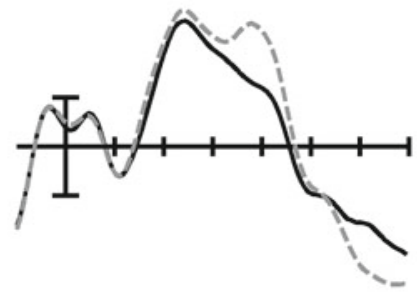

$\mathrm{Cz}$

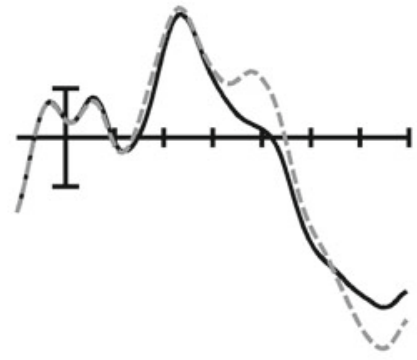

Pz

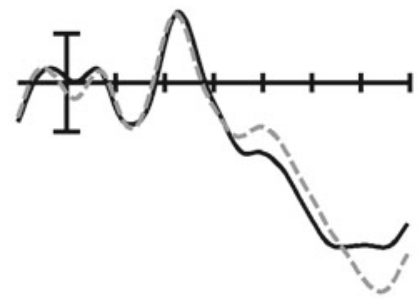

$\mathrm{Oz}$

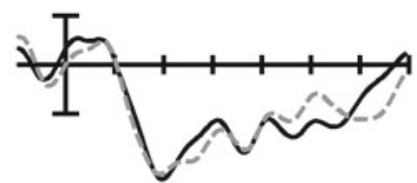

$2 \mu \mathrm{v}$

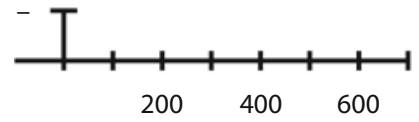

FP2

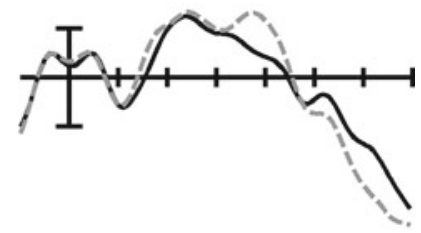

F4

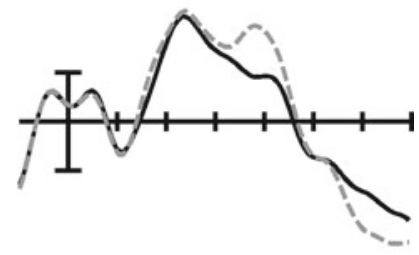

C4

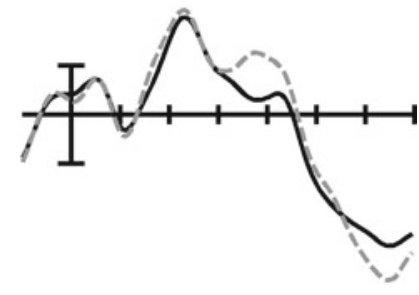

P4
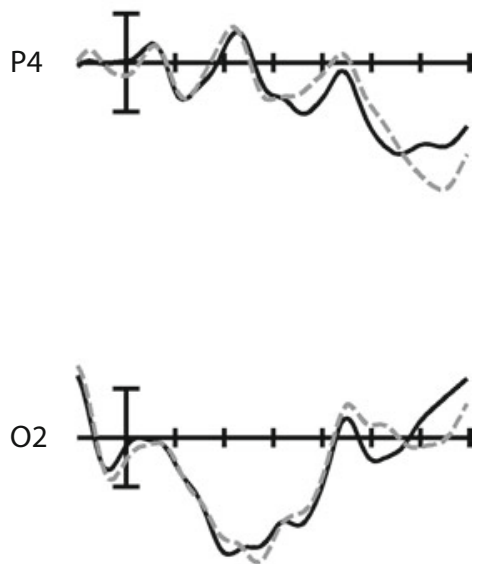

Related

-ோ=ー- Unrelated

Figure 6. ERPs from 15 scalp sites time-locked to target pictures in the English (L1) picture naming block with French (L2) prime words. Target onset is marked by the vertical calibrating bar, and each tick mark on the $x$-axis represents $100 \mathrm{msec}$.

Distributional analyses. In contrasts of the priming effect (unrelated - related) across the three measurement windows, there were significant anterior-posterior $\times$ laterality $\times$ epoch interactions for both the raw mean amplitude values $[F(16,240)=3.01, p=.0001]$ and for those normalized separately for each measurement window $[F(16,240)=$
$2.46, p=.0018]$. Follow-up analyses contrasting the early and middle windows and the middle and late windows revealed this same significant interaction (all $p \mathrm{~s}<.03$ ).

Language-switch effects. There were no significant switch effects in any of the analysis windows in this experiment. 
A
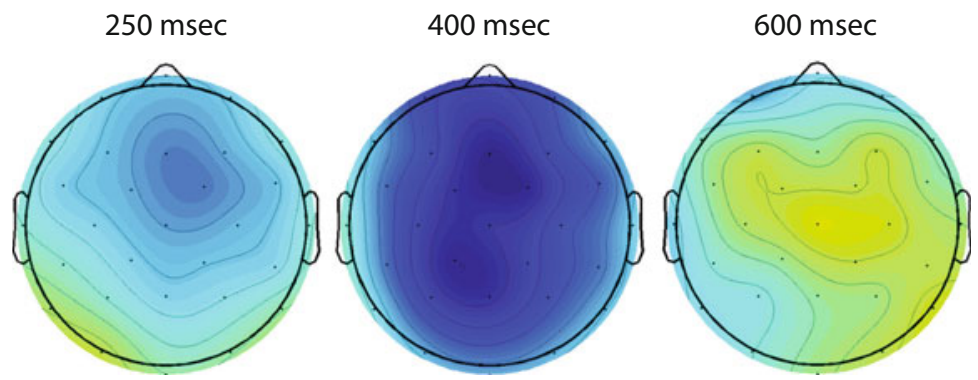

B
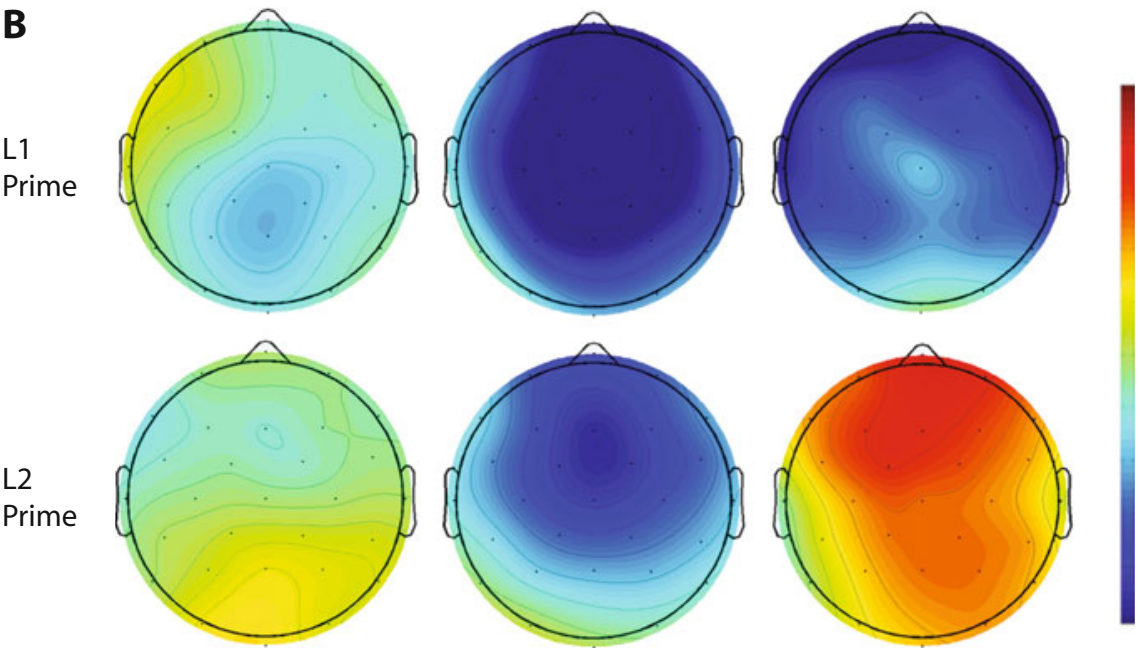

C

C
L2
Prime
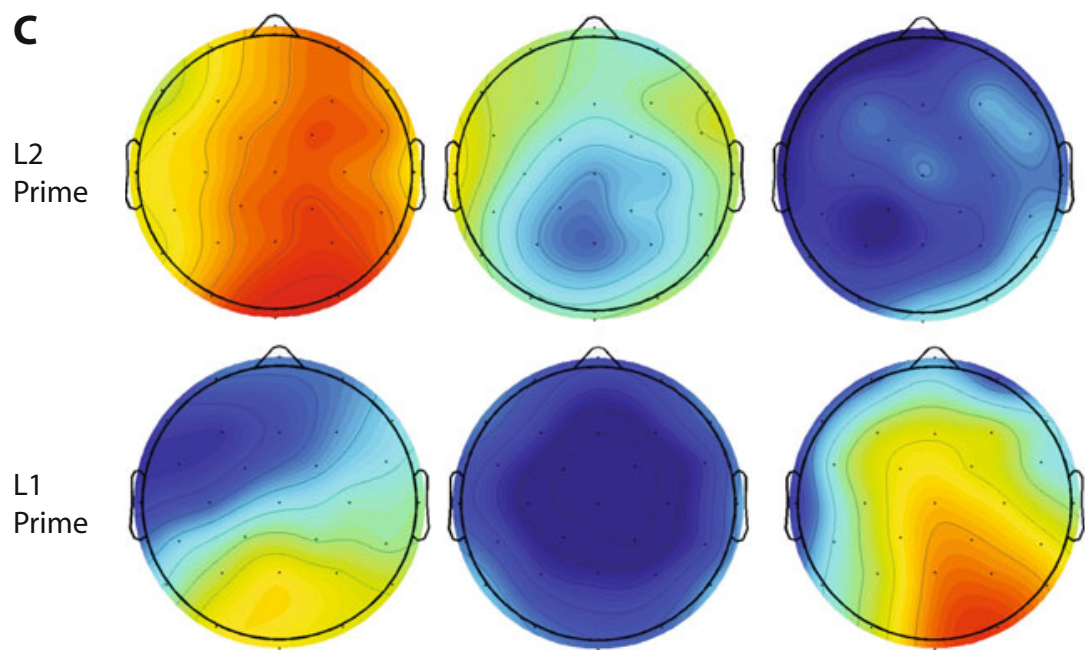

Figure 7. Voltage maps at three latencies computed by subtracting the related target ERPs from the unrelated target ERPs and plotting the interpolated voltage differences from 29 scalp sites (voltage scale in microvolts). (A) Experiment 1: The early, somewhat anterior effect of priming can be seen as the darker area in the 250 -msec plot, and the large, widely distributed priming effect can be clearly seen in the $400-\mathrm{msec}$ plot. Finally, the small anterior priming effects are visible in the 600-msec map. (B) Experiment 2A: Voltage maps resulting from subtracting the related target ERPs from the unrelated target ERPs in the L1-L1 (top) and L2-L1 (bottom) conditions, when pictures were named in English (L1). (C) Experiment 2B: Voltage maps resulting from subtracting the related target ERPs from the unrelated target ERPs in the L2-L2 (top) and L1-L2 (bottom) conditions. A full-color view of this figure appears in the online publication of this article. 
Behavioral results. Due to equipment malfunction, the naming data from 1 participant were not available. The average naming accuracy and naming latency from the remaining 15 participants for both prime languages and for related and unrelated prime-target pairs are listed in Table 4. Repeated measure ANOVAs were conducted with prime-target relatedness and prime language as withinparticipants factors. Targets with English primes were named more accurately than were targets with French primes $[F(1,15)=8.09, p=.012]$, and targets preceded by related primes were named more accurately than were targets following unrelated primes $[F(1,15)=6.65, p=$ $.021]$. However, there was also a language $\times$ relatedness interaction $[F(1,15)=11.35, p=.004]$, due to the fact that only targets following English primes showed a priming effect.

For naming RTs, there were main effects of prime language $[F(1,14)=6.27, p=.0252]$, with target pictures following English primes being named faster than those following French primes, and prime-target relatedness $[F(1,14)=13.63, p=.0024]$, with targets following unrelated prime words being named slower than those following primes that named the target. There was also a significant interaction of language and relatedness $[F(1,14)=$ 9.91, $p=.0071]$, with target pictures following English primes showing a much bigger discrepancy in naming latency between related and unrelated primes than target pictures following French primes. Follow-up ANOVAs revealed that the $138-\mathrm{msec}$ difference in naming latency for targets following related and unrelated English primes was significant $[F(1,14)=23.86, p=.0002]$, whereas the 23 -msec difference for targets following French primes was not $(p>.44)$.

\section{Results: Experiment 2B}

ERP results. Figure 8 shows ERPs time-locked to target pictures preceded by French prime words that are either unrelated to the target picture (L2-L2-unrelated) or are the picture name in French (L2-L2-related). Figure 9 shows ERPs to the same target pictures preceded by either unrelated English prime words (L1-L2-unrelated) or the picture name in English (L1-L2-related). The voltage maps resulting from subtracting the related-target ERPs from the unrelated-target ERPs in the L2-L2 (top) and L1-L2 (bottom) conditions are plotted in Figure 7C.

In the 200- to $300-\mathrm{msec}$ epoch, the omnibus ANOVA produced a significant relatedness $\times$ anterior-posterior $\times$ laterality interaction $[F(8,120)=2.43, p=.0179]$

Table 4

Percentage of Objects Named Correctly and Mean Naming Latencies (Response Times, in Milliseconds) in English

\begin{tabular}{lccccc}
\hline & \multicolumn{5}{c}{ Naming Latency } \\
\cline { 2 - 6 } & \% Correct & Priming & $M$ & $S D$ & Priming \\
\hline English & & & & & \\
$\quad$ Related & 97.6 & 8.2 & 1,133 & 114 & 138 \\
$\quad$ Unrelated & 89.4 & & 1,271 & 115 & \\
French & & & & & \\
$\quad$ Related & 90.4 & 0.1 & 1,258 & 135 & 23 \\
$\quad$ Unrelated & 90.3 & & 1,281 & 116 & \\
\hline
\end{tabular}

and a significant relatedness $\times$ language $\times$ anteriorposterior $\times$ laterality interaction $[F(8,120)=2.05, p=$ .0463]. Separate follow-up analyses were run to decompose this interaction. Target ERPs following English primes revealed reliable priming $[F(8,120)=3.17, p=$ $.0027]$, suggesting that the related English prime word condition was less negative than the unrelated English prime word condition, especially at more anterior sites (see Figures 8 and 9). In the French follow-up analyses, there was a relatedness $\times$ anterior-posterior interaction $[F(4,60)=4.06, p=.0056]$. Target pictures following French prime words produced the opposite pattern from targets following English primes, with larger negativity for related than for unrelated prime words, especially at more posterior sites.

The omnibus ANOVA in the 300- to 500-msec epoch produced a significant main effect of relatedness $[F(1,15)=$ 9.14, $p=.0085]$ and a relatedness $\times$ anterior-posterior $\times$ laterality interaction $[F(8,120)=2.58, p=.0125]$, but no relatedness $\times$ language interaction. Because this latter interaction was not significant, we did not conduct separate prime-language follow-up analyses, although it is clear from Figures 8 and 9 that both prime languages produced clear priming effects in this epoch (i.e., targets following unrelated primes were more negative than targets following related primes).

The omnibus ANOVA in the 500- to 700-msec window revealed a prime language $\times$ relatedness $\times$ anteriorposterior $\times$ laterality interaction $[F(8,120)=2.57, p=$ .0126]. English prime follow-up analyses revealed a significant relatedness $\times$ anterior-posterior interaction $[F(4,60)=4.68, p=.0024]$, with target pictures following English primes producing a more negative-going response at anterior sites in the unrelated condition but a more negative-going response at posterior sites in the related condition. In the French prime follow-up analyses, there was a relatedness $\times$ anterior-posterior $\times$ laterality interaction $[F(8,120)=4.01, p=.0003]$. Target pictures preceded by French primes produced a more negativegoing response in the unrelated than in the related condition, especially at anterior and left-hemisphere sites.

Distributional analyses. In contrasts of the priming effect (unrelated - related) across the three measurement windows, there were significant anterior-posterior $\times$ laterality $X$ epoch interactions for both the raw mean amplitude values $[F(16,240)=4.05, p=.0001]$ and for those normalized separately for each measurement window $[F(16,240)=$ $4.00, p=.0001]$. Follow-up analyses contrasting the early and middle windows and the middle and late windows revealed this same significant interaction (all $p \mathrm{~s}<.02$ ).

Language-switch effects. We also contrasted target pictures preceded by unrelated English and unrelated French words (switch and no-switch trials). In the early window (200-300 $\mathrm{msec})$, there was a significant main effect of switch $[F(1,15)=19.05, p=.0006]$, with targets following a prime in French (no switch) producing a more positive-going response than targets following a word in English (switch) (see Figure 10). There were no switch effects in the middle window, but there was a significant switch $\times$ anterior-posterior $\times$ laterality interaction for 

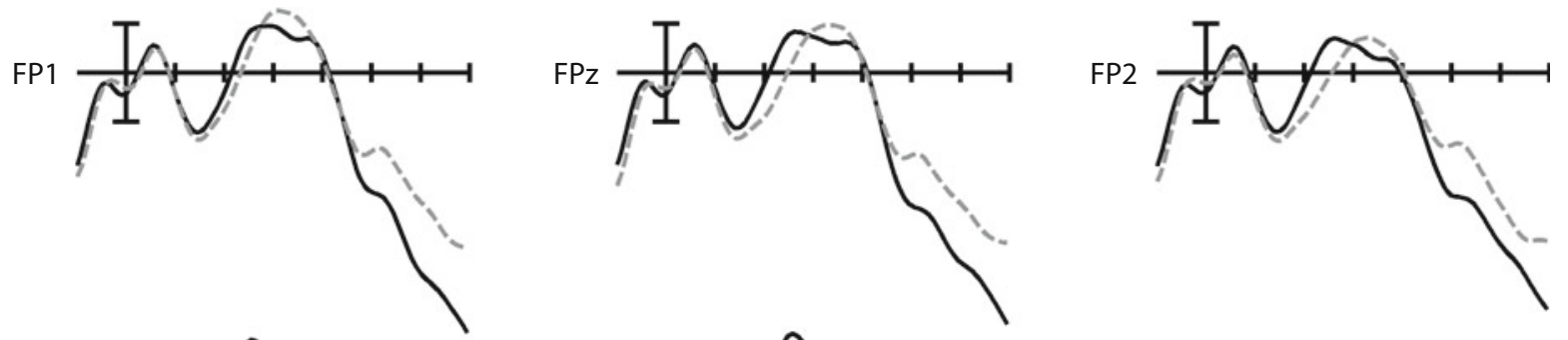

F3
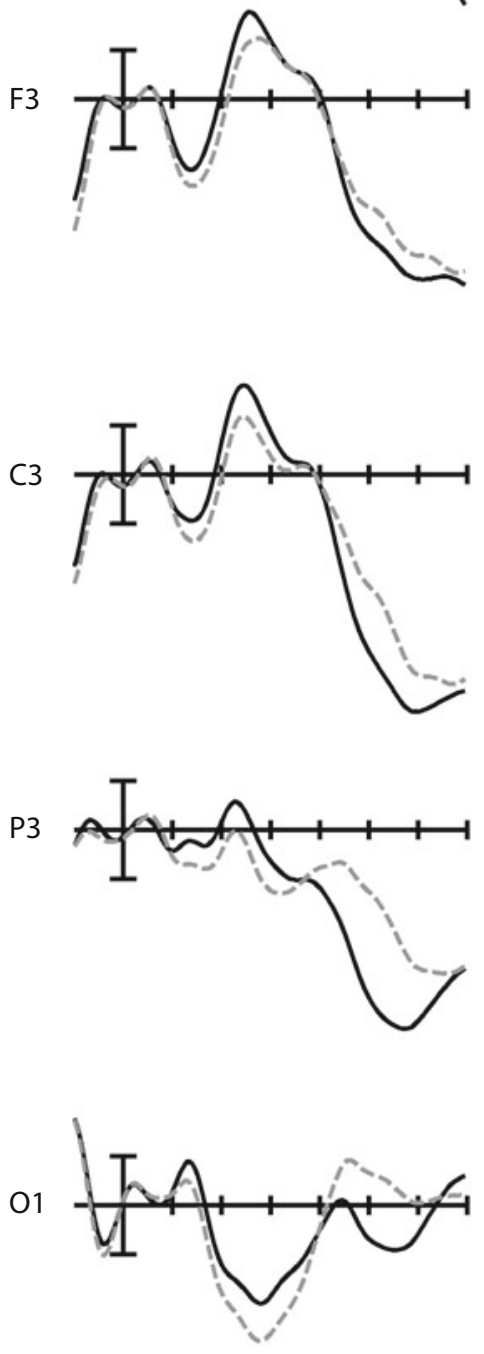
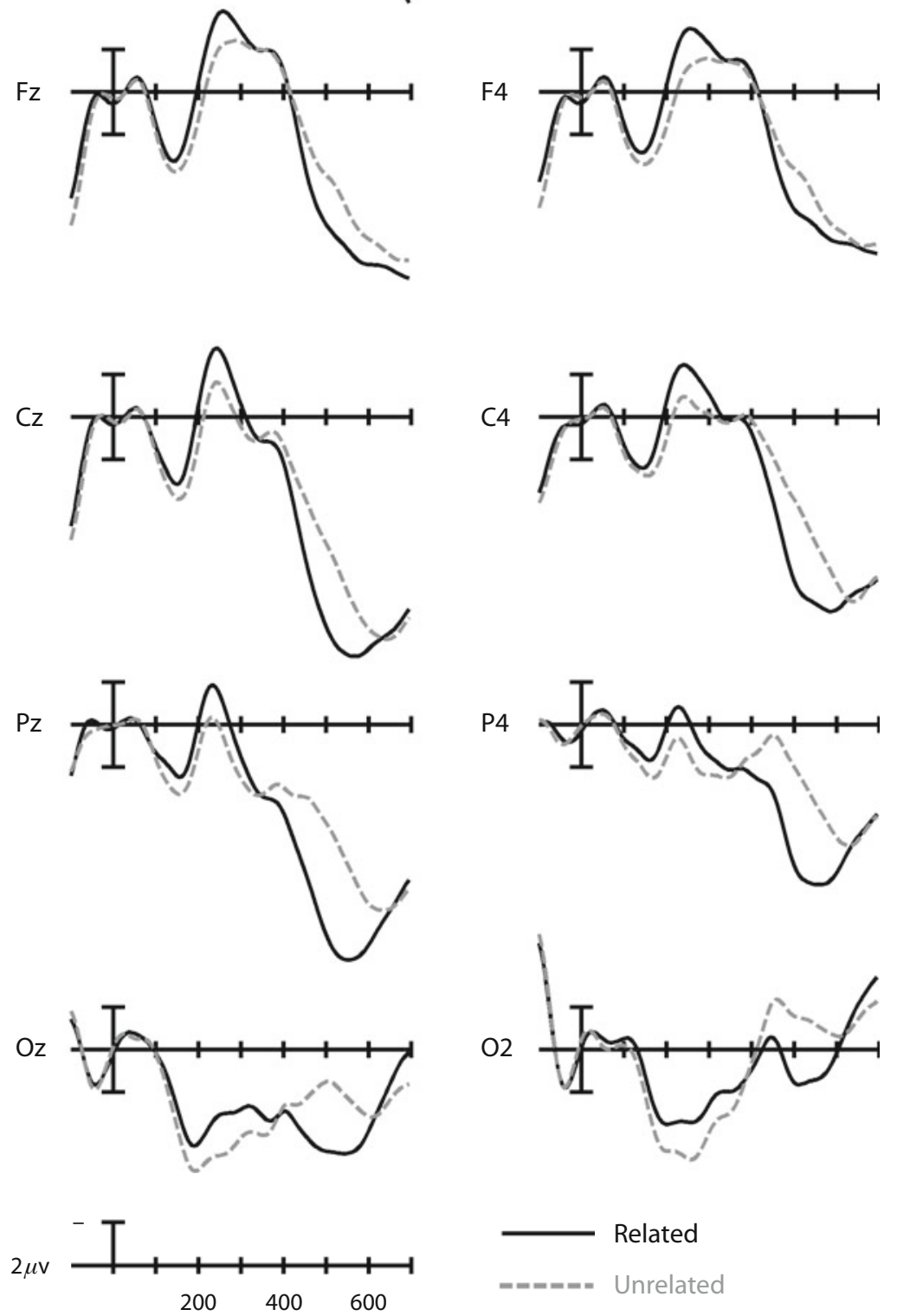
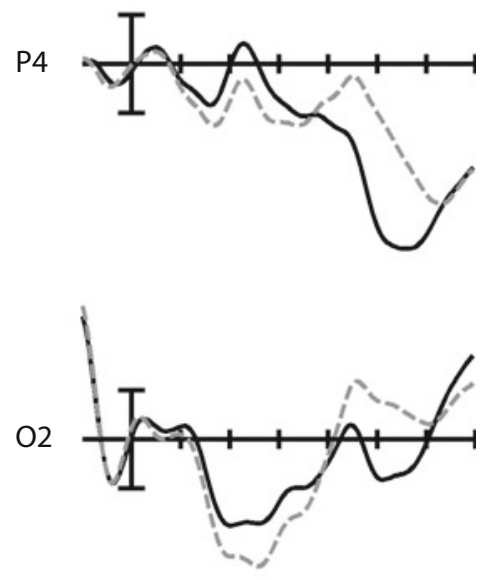

Related

Unrelated

Figure 8. Target pictures named in French (L2) preceded by French (L2) prime words.

the late window $[F(8,120)=2.5, p=.0153]$. The latter effect appears to be due to a larger positivity on switch trials at central and posterior sites but a larger negativity at right-hemisphere anterior sites.

Behavioral results. When participants were asked to name pictures in French (L2), they named targets with French primes more accurately than they did targets with English primes, showing a main effect of language
$[F(1,15)=16.99, p=.0009]$ (see Table 5). Targets preceded by related primes were named more accurately than were targets preceded by unrelated primes, showing a main effect of relatedness $[F(1,15)=24.89, p=.0002]$. Additionally, the interaction between language and relatedness was significant, because only for French primes was there an increase in accuracy for related, as compared with unrelated, primes $[F(1,15)=12.97, p=.003]$. 
FP1

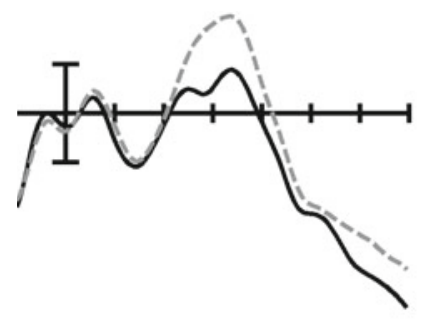

F3

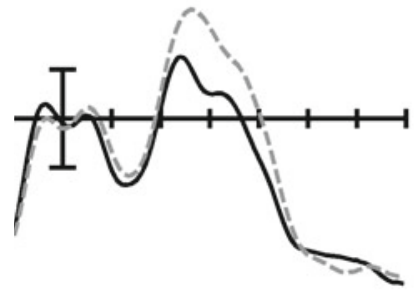

C3

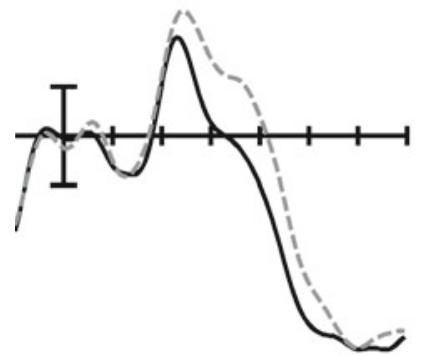

P3

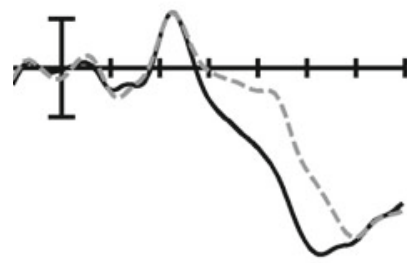

01

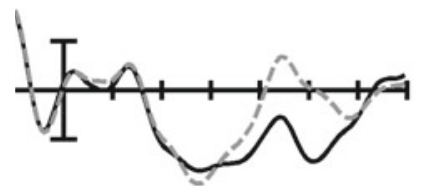

$\mathrm{FPz}$
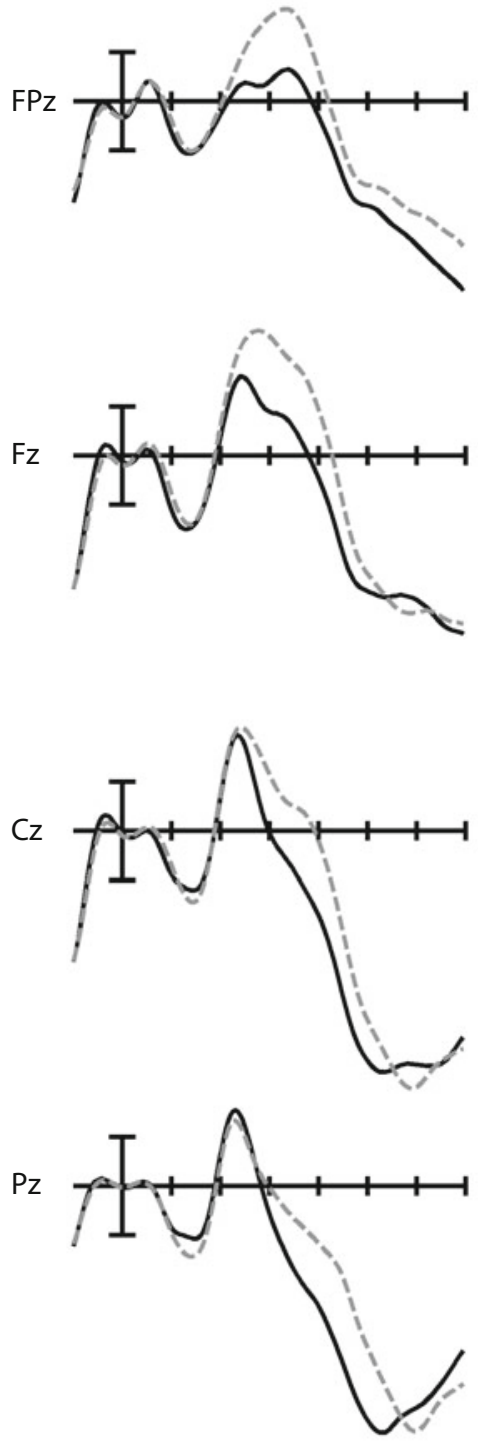

$\mathrm{Oz}$

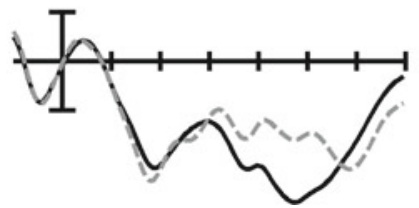

$2 \mu \mathrm{v}$

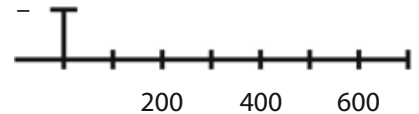

FP2

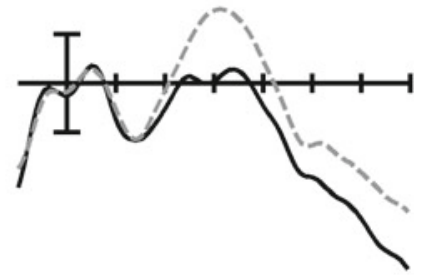

F4

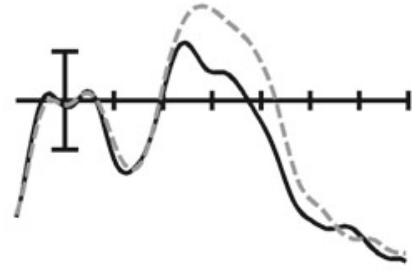

C4

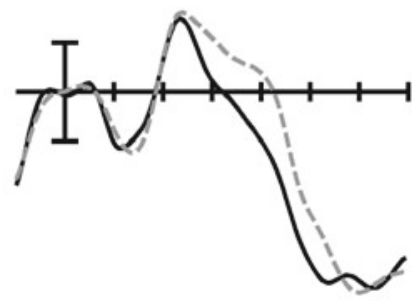

P4

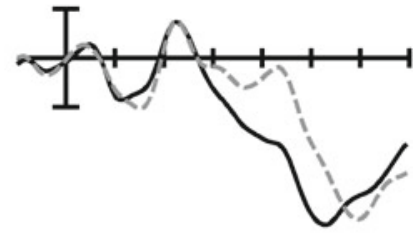

$\mathrm{O} 2$

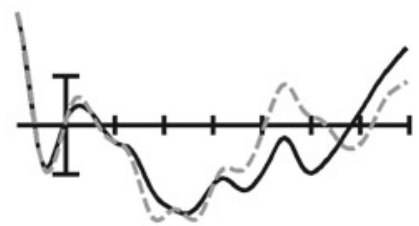

Related

Unrelated

Figure 9. Target pictures named in French (L2) preceded by English (L1) prime words.

For naming RTs, there were main effects of prime language $[F(1,15)=11.16, p=.0045]$, with target pictures following French primes being named faster than those following English primes, and of prime-target relatedness $[F(1,15)=69.07, p<.0001]$, with targets following unrelated prime words being named slower than those following primes that named the target. There was also a signifi- cant interaction of language and relatedness $[F(1,15)=$ $14.42, p=.0018]$, with target pictures following French primes showing a bigger discrepancy in naming latency between the related and unrelated conditions than target pictures following English primes. Follow-up ANOVAs revealed that the $269-\mathrm{msec}$ difference in naming latency for targets following related and unrelated French primes 
FP1

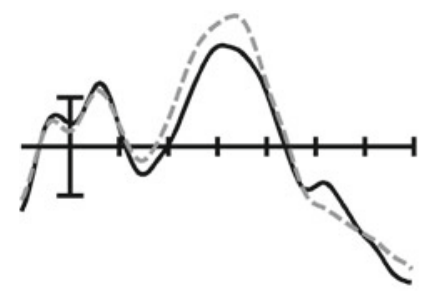

F3

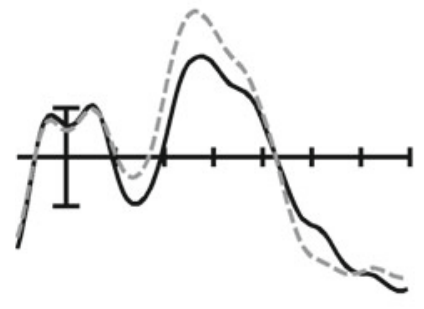

C3

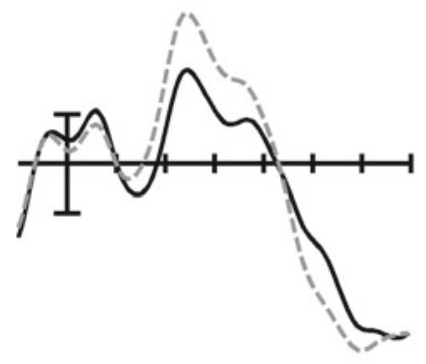

P3

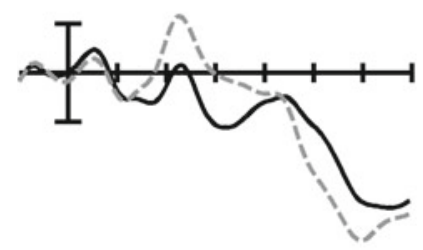

01

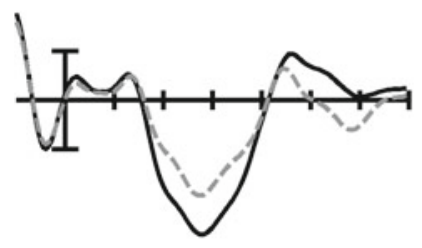

$\mathrm{FPz}$

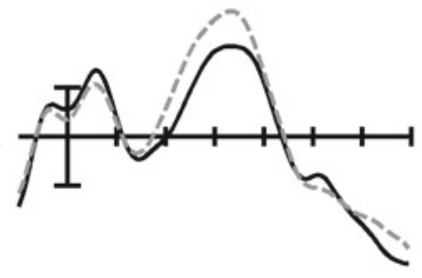

$\mathrm{Fz}$

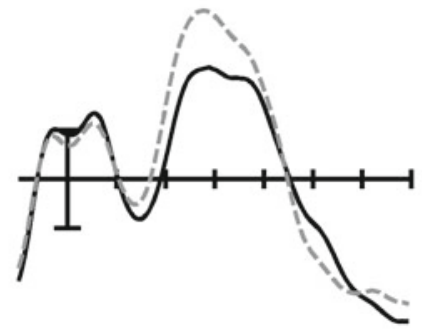

$\mathrm{Cz}$

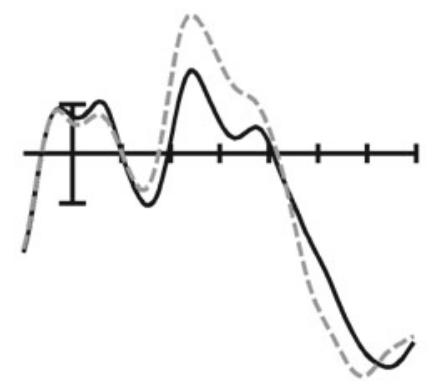

$\mathrm{Pz}$

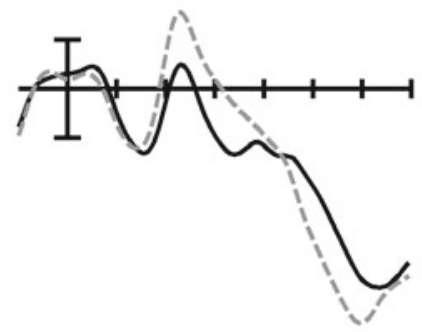

$\mathrm{Oz}$
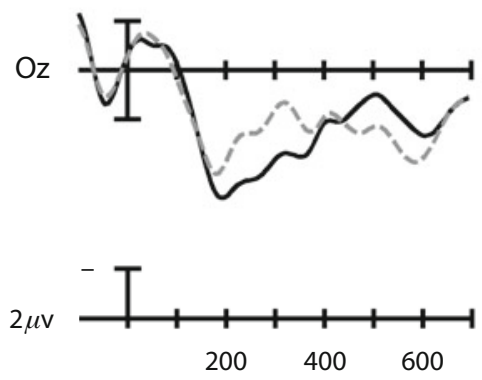

FP2

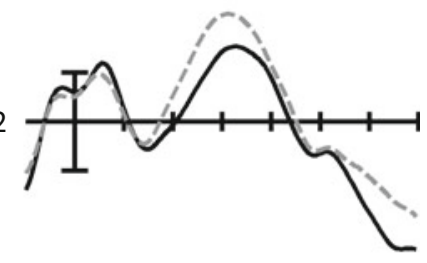

F4

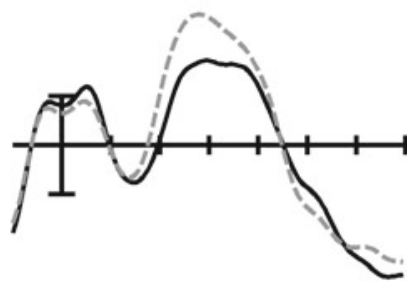

C4

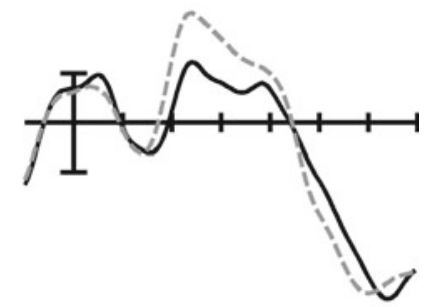

P4

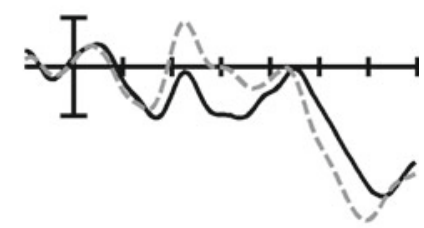

$\mathrm{O} 2$

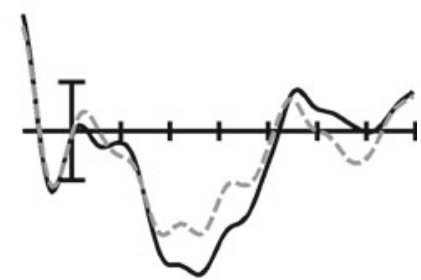

Related

------ Unrelated

Figure 10. Target pictures named in French (L2) preceded by unrelated French (no switch) and English (switch) prime words.

was significant $[F(1,15)=69.12, p<.0001]$, as was the 135 -msec difference for targets following English primes $[F(1,15)=27.98, p=.0001]($ see Table 5).

\section{Discussion}

As in Experiment 1, there were robust effects of wordpicture priming. Masked prime words differentially mod- ulated ERPs time-locked to the following picture targets as a function of prime-target relatedness. The English (L1) prime condition of Experiment 2A provided a direct replication of Experiment 1 with a group of bilingual participants. Significant L1-L1 repetition priming effects were seen in the same three time windows as were used to analyze the results of Experiment 1, starting at 
Table 5

Percentage of Objects Named Correctly and Mean Naming Latencies (Response Times, in Milliseconds) in French

\begin{tabular}{lccccc}
\hline & \multicolumn{5}{c}{ Naming Latency } \\
\cline { 2 - 6 } & \% Correct & Priming & $M$ & $S D$ & Priming \\
\hline French & & & & & \\
$\quad$ Related & 93.3 & 13.1 & 1,113 & 115.42 & 269 \\
$\quad$ Unrelated & 80.2 & & 1,382 & 174.04 & \\
English & & & & & \\
$\quad$ Related & 81.6 & 1.1 & 1,266 & 131.61 & 135 \\
$\quad$ Unrelated & 80.5 & & 1,401 & 171.40 & \\
\hline
\end{tabular}

$200 \mathrm{msec}$ and ending at $700 \mathrm{msec}$, well before there was any evidence for articulator artifact. The behavioral results showed significant priming from same-name primes, as in Experiment 1, as well as significant facilitation from translation primes. This result is in line with the semantic facilitation effect reported by Finkbeiner and Caramazza (2006) in a similar masked-priming paradigm combined with picture naming.

Probably the most important result of Experiment 2 is the fact that L1 prime words significantly modulated ERPs to picture targets named in L2 (Experiment 2B). These cross-language priming effects were particularly robust in the 200- to 300-msec and 300- to 500-msec time windows, and the timing and scalp distribution of the effects were similar to the within-language (L1-L1) repetition priming effect. This result strongly suggests that phonological and/or articulatory representations are unlikely to be the source of the priming effects seen in these same time windows in Experiment 1. A picture name in L2 (e.g., camion) and its noncognate translation prime in L1 (e.g., truck) do not have more phonological overlap than do picture names and unrelated prime words. This therefore points to object representations and/or amodal semantic representations as being the source of these particular priming effects.

The priming effect in the 200- to $300-\mathrm{msec}$ time window seen in the L1-L1 and L1-L2 conditions was not significant when pictures were named in $\mathrm{L} 1$ and primes were presented in L2 (L2-L1). This can be explained by the overall longer time required for L2 prime words to activate semantic representations, as compared with that required for L1 primes (e.g., Midgley et al., 2009). Priming effects did emerge in the 300 - to 500 -msec time window in this condition, but they were still significantly smaller compared with the L1-L1 priming effect. More interesting, however, is the fact that there was no significant L2-L1 priming in the late 500- to 700-msec time window. Given that there was significant priming in the 300 - to $500-\mathrm{msec}$ window in this condition, this particular result suggests that the late priming effect is sensitive to whether or not the prime word is in the same language as the target-naming language. This result therefore points to word-specific phonological/articulatory representations as the basis of priming effects seen for within-language repetitions in the 500- to 700-msec time window. Further evidence for this was seen in the L1-L2 priming effect in this same time window, where related primes generated increased rather than decreased negativity in posterior sites.
Finally, when pictures were named in French and primes were French words (L2-L2), the early frontal priming effect seen in Experiment 1, as well as in the L1-L1 and L1-L2 conditions of Experiment 2, took the form of a reversed priming effect. Our tentative interpretation of this pattern is that it reflects a complex interaction between the effects of masked primes and effects that are driven by mechanisms specific to picture naming in L2. One mechanism that has been proposed to be specific to picture naming in L2 is the active suppression of L1 lexical representations (Green, 1998; Meuter \& Allport, 1999). This suppression mechanism is part of a standard account of switch costs in bilingual language production, such that naming a picture in L2 slows naming of the same picture in L1 on the following trial (e.g., Costa \& Santesteban, 2004). In the present study, we found an effect of language switching (prime in same language as the target naming language, or not) in the ERP waveforms when naming pictures in L2. Unrelated prime words in $\mathrm{L} 1$ generated greater negativities than did unrelated prime words in L2. This switch effect was particularly evident in the early negative-going component that peaked between 200 and 300 msec post target onset (see Figure 10). One possible interpretation of the switch effects seen in the present experiment is that the L1 prime word interferes with the active suppression of L1 lexical representations during picture naming in L2. No switch effects were seen in L1 picture naming, possibly because there is less need to suppress L2 lexical representations during picture naming in L1.

\section{GENERAL DISCUSSION}

To our knowledge, the present study is the first to combine masked priming and ERP recordings in the study of basic processes in picture naming. In two experiments testing a group of monolingual and a group of bilingual participants, we found significant influences of masked prime words on the ERPs generated during the first $700 \mathrm{msec}$ of target picture processing, well before articulatory onset and free from articulation-induced artifacts. Indeed, average picture-naming latencies were well over $1 \mathrm{sec}$ in the present study, hence allowing the recording of artifact-free EEGs during the key phases of the picture-naming process prior to articulation. From a purely methodological perspective, this study therefore demonstrates that artifactfree ERPs can be measured during picture naming (see also Christoffels et al., 2007; Verhoef et al., 2009) and, furthermore, that these ERPs can be modulated by a masked prime word shown briefly prior to picture onset.

Experiment 1 used a simple repetition priming manipulation in which prime words could correspond either to the picture target's name or to the name of an unrelated picture. Primes were presented for $70 \mathrm{msec}$ and were followed by a pattern mask for $50 \mathrm{msec}$, followed immediately by the picture target. Priming effects were evident in the ERP waveforms starting around $200 \mathrm{msec}$ and continuing through to about $700 \mathrm{msec}$ post target onset, with more negative-going waveforms following unrelated primes. The priming effects seen between 200 and $700 \mathrm{msec}$ post target onset appeared to be separable into 
three distinct components peaking just after $200 \mathrm{msec}$, at around $400 \mathrm{msec}$, and at about $550 \mathrm{msec}$. This interpretation is supported by the significantly different distribution of priming effects across the three temporal epochs.

Experiment 2 was designed to test different possible loci of the priming effects found in Experiment 1. The different loci were described within generic interactive activation accounts of word recognition and picture naming and included structural representations of objects, amodal semantic representations, lexical phonology (lexemes), segmental phonology (phonemes), and articulatory output representations. This analysis was further simplified by regrouping the phonological and articulatory representations into a single word-specific component, leading to three principal sources of the priming effects: object-specific form representations, amodal semantic representations, and word-specific phonological/articulatory representations. These three potential sources of priming effects were tentatively linked to the three ERP components revealed by our priming manipulation in Experiment 1. Priming effects in the earliest component were hypothesized to reflect preactivation of object representations by prime words. Priming effects in the second component were hypothesized to reflect preactivation of amodal semantic representations by prime words. Priming effects in the third component were hypothesized to reflect preactivation of word-specific phonology by prime words.

Experiment 2 provided a preliminary test of this tentative linkage of ERP components and component processes in word recognition and picture naming. Experiment 2 tested bilingual participants who were asked to name picture targets in their L1 and L2, primed either by the picture name in the same language or its translate in the other language. Priming effects measured relative to unrelated prime words from the same language as the related prime showed early effects in the ERP waveforms once again when primes were in L1. Most important is that these early priming effects were highly robust when primes were translates of the picture name. These L1-L2 translation priming effects were also robust in the later component, which peaked at around $400 \mathrm{msec}$ post target onset. These results point to structural representations of pictures and amodal semantic representations as being likely sources of the observed modulation of ERPs in these two time windows.

On the other hand, Experiment 2 provided some evidence that ERPs in the 500- to 700-msec time window were sensitive to whether or not the prime was from the same language as the target-naming language. There was no significant priming in this component with L2 primes and picture naming in L1, even though there were significant priming effects on the N400 in this condition. When primes were in L1 and pictures were named in L2, there was a reversal of the priming effect at posterior sites that was not seen in either the L1-L1 or L2-L2 priming conditions. These distinct patterns seen in the within-language (L1-L1, L2-L2) and between-language (L1-L2, L2-L1) conditions suggest that word-specific phonological representations could be the source of the priming effects seen in the late component. The timing of this effect may ap- pear to be relatively late, as compared with estimates of the time course of phonological encoding from behavioral studies of picture naming, but this could be due to the relatively slow naming latencies in the present study, as well as to possible interference effects from the prime and masking stimuli that preceded picture targets.

Experiment 2 also found evidence for switch effects in picture naming with masked prime words. The language of the prime word (in the unrelated prime condition) was found to affect ERPs generated during picture naming in L2, with greater negativities in the 200- to 300 -msec time window when primes were in L1 (switch), as compared with when primes were in L2 (no switch). No such switch effect was seen when pictures were named in L1. A similar pattern of switch effects was reported by Jackson, Swainson, Cunnington, and Jackson (2001) in a digit-naming task. Digit naming in L2 generated a more negative-going frontal N2 component when the directly preceding trial involved digit naming in L1, as compared with when it involved digit naming in L2. Following these authors, we suggest that this pattern of results fits with the hypothesis that L2 language production entails active suppression of L1 lexical representations, whereas production in L1 does not necessitate the same degree of suppression of L2 lexical representations. This hypothesis is typically evoked to explain the asymmetrical nature of switch costs seen in bilingual language production, when the naming language changes unpredictably from trial to trial by use of a cue that indicates the language to be used. In these conditions, a switch from naming in L2 to naming in L1 generates a greater cost than do switches from L1 to L2 (Meuter \& Allport, 1999), except in highly proficient bilinguals (Costa \& Santesteban, 2004). We suggest that the presence of L1 prime words interferes in the process of suppressing L1 lexical activation during picture naming in L2, creating a conflict that is reflected in the ERP waveforms starting around 200 msec post target onset.

Furthermore, we very tentatively suggest that the unusual reversed priming effect seen in this same early component (200-300 $\mathrm{msec}$ ) with L2 primes and L2 picture naming is due to a complex interaction between priming effects and the process of suppressing L1 lexical activation. The presence of L2 word primes should facilitate the process of L1 suppression, leading to the strongest inhibition of L1 lexical representations in these conditions. Any form of translation (implicit or explicit; see, e.g., Kroll \& Stewart, 1994) of the L2 prime word into its L1 equivalent might therefore generate processing conflicts in these conditions, and the likelihood of translating a prime word could well depend on its relatedness to the picture target. In any case, this particular phenomenon clearly needs to be explored in future research.

What conclusions can be drawn from the results of Experiment 2, with respect to models of bilingual language comprehension and production? At a very general level of theorizing, the presence of cross-language priming effects in both the behavioral and the ERP data is in line with models that allow a certain amount of processing to occur in the nontarget language. In the specific case of language production, this means that producing words in a given lan- 
guage does not involve a complete shutdown of processing associated with the other language (Costa, Caramazza, \& Sebastian-Galles, 2000; Kroll, Bobb, \& Wodniecka, 2006). A general model that allows such cross-language permeability is the BIA model (Grainger \& Dijkstra, 1992; van Heuven, Dijkstra, \& Grainger, 1998) and its successor, the BIA + model (Dijkstra \& van Heuven, 2002). These models posit that L2 words gain access to semantics in much the same way as L1 words do, but that they require more time, given the overall lower exposure to L2 words, as compared with that to L1 words, in unbalanced bilinguals. It is the slower processing of L2 primes that can account for why these primes did not affect picture naming in L1 in the 200- to $300-\mathrm{msec}$ time window in the present study. Applied to the question of bilingual language production, the BIA model would allow phonological forms from both languages to be coactivated to a certain extent, with interference being controlled by the active suppression of nontarget-language representations. This would occur via top-down inhibition from language nodes to word-form representations in the original BIA model, or via more general executive control mechanisms, as proposed by Green (1998; see also Hernandez \& Meschyan, 2006).

Finally, the behavioral facilitation found with noncognate translation primes in Experiment 2 is in line with the pattern found by Finkbeiner and Caramazza (2006) with semantically related primes. According to Finkbeiner and Caramazza, this is evidence against competitive interactions between phonological word forms during selection for production. However, in the case of translation primes, as in the present study, this finding could also be interpreted in terms of global inhibition of phonological word forms in the language of the prime stimuli, which would effectively cancel any influence of such representations during lexical selection. In this case, semantic influences could emerge in the absence of an influence of phonological word forms. A similar interpretation can be offered for the results of Costa, Miozzo, and Caramazza (1999), who failed to find semantic interference from translation equivalents in the picture-word interference paradigm.

\section{Conclusions}

The present study examined the feasibility of combining an immediate naming procedure with masked priming and electrophysiological recordings as a means for probing the time course of component processes in picture naming. The ERP signal generated during picture naming was found to be sensitive to the relationship between the picture name and a masked prime word briefly presented prior to the appearance of picture targets. Different patterns of priming effects were found to be functions of time from picture onset and whether or not primes and targets were in participants' first or second language, thus revealing the sensitivity of the technique and its potential for future research.

\section{AUTHOR NOTE}

This research was supported by NIH Grants HD043251 and HD25889. Correspondence concerning this article should be addressed to P. J. Holcomb, Psychology Bldg., Tufts University, Medford, MA 02155 (e-mail: pholcomb@tufts.edu).

\section{REFERENCES}

Biederman, I. (1987). Recognition-by-components: A theory of human image understanding. Psychological Review, 94, 115-147.

Christoffels, I. K., Firk, C., \& Schiller, N. O. (2007). Bilingual language control: An event-related brain potential study. Brain Research, 1147, 192-208.

Costa, A., Caramazza, A., \& Sebastian-Galles, N. (2000). The cognate facilitation effect: Implications for models of lexical access. Journal of Experimental Psychology: Learning, Memory, \& Cognition, 26, 1283-1296.

Costa, A., Miozzo, M., \& Caramazza, A. (1999). Lexical selection in bilinguals: Do words in the bilingual's two lexicons compete for selection? Journal of Memory \& Language, 41, 365-397.

Costa, A., \& Santesteban, M. (2004). Lexical access in bilingual speech production: Evidence from language switching in highly proficient bilinguals and L2 learners. Journal of Memory \& Language, 50, 491-511.

Dell, G. S. (1986). A spreading-activation theory of retrieval in sentence production. Psychological Review, 93, 283-321.

Diependaele, K., Ziegler, J. C., \& Grainger, J. (in press). Fast phonology and the bi-modal interactive-activation model. European Journal of Cognitive Psychology.

Dijkstra, T., \& van Heuven, W. J. B. (2002). The architecture of the bilingual word recognition system: From identification to decision. Bilingualism: Language \& Cognition, 5, 175-197.

EdDY, M., Schmid, A., \& Holcomb, P. J. (2006). Masked repetition priming and event-related brain potentials: A new approach to tracking the time-course of object perception. Psychophysiology, 43, 564-568.

Ferrand, L., Grainger, J., \& Segui, J. (1994). A study of masked form priming in picture and word naming. Memory \& Cognition, 22, 431-441.

Finkbeiner, M., \& Caramazza, A. (2006). Now you see it, now you don't: On turning semantic interference into facilitation in a Strooplike task. Cortex, 42, 790-796.

Finkbeiner, M., Gollan, T. H., \& Caramazza, A. (2006). Lexical access in bilingual speakers: What's the (hard) problem? Bilingualism: Language \& Cognition, 9, 153-166.

ForSTER, K. I. (1998). The pros and cons of masked priming. Journal of Psycholinguistic Research, 27, 203-233.

Forster, K. I., \& Davis, C. (1984). Repetition priming and frequency attenuation in lexical access. Journal of Experimental Psychology: Learning, Memory, \& Cognition, 10, 680-698.

Grainger, J., Diependaele, K., Spinelli, E., Ferrand, L., \& Farioli, F. (2003). Masked repetition and phonological priming within and across modalities. Journal of Experimental Psychology: Learning, Memory, \& Cognition, 29, 1256-1269.

Grainger, J., \& DiJKstra, A. (1992). On the representation and use of language information in bilinguals. In R. J. Harris (Ed.), Cognitive processing in bilinguals (pp. 207-220). Amsterdam: Elsevier.

Grainger, J., \& Holcomb, P. J. (2009). Watching the word go by: On the time-course of component processes in visual word recognition. Language \& Linguistics Compass, 3, 128-156.

Grainger, J., Kiyonaga, K., \& Holcomb, P. J. (2006). The time-course of orthographic and phonological code activation. Psychological Science, 17, 1021-1026.

Grainger, J., \& Ziegler, J. C. (2007). Cross-code consistency effects in visual word recognition. In E. L. Grigorenko \& A. Naples (Eds.), Single-word reading: Biological and behavioral perspectives (pp. 129-157). Mahwah, NJ: Erlbaum.

GreEN, D. W. (1998). Mental control of the bilingual lexico-semantic system. Bilingualism: Language \& Cognition, 1, 67-81.

Greenhouse, S. W., \& Geisser, S. (1959). On methods in the analysis of profile data. Psychometrika, 24, 95-112.

Henson, R. N., Mouchlianitis, E., Matthews, W. J., \& Kouider, S. (2008). Electrophysiological correlates of masked face priming. NeuroImage, 40, 884-895.

Hernandez, A. E., \& Meschyan, G. (2006). Executive function is necessary to enhance lexical processing in a less proficient L2: Evidence from fMRI during picture naming. Bilingualism: Language \& Cognition, 9, 177-188.

Holcomb, P. J., \& Grainger, J. (2006). On the time-course of visual word recognition: An event-related potential investigation using 
masked repetition priming. Journal of Cognitive Neuroscience, 18, 1631-1643.

Holcomb, P. J., \& Grainger, J. (2007). Exploring the temporal dynamics of visual word recognition in the masked repetition priming paradigm using event-related potentials. Brain Research, 1180, 39-58.

JaCKSON, G. M., Swainson, R., Cunnington, R., \& JaCkson, S. R. (2001). ERP correlates of executive control during repeated language switching. Bilingualism: Language \& Cognition, 4, 169-178.

JACOBS, A. M., \& GRAINGER, J. (1991). Automatic letter priming in an alphabetic decision task. Perception \& Psychophysics, 49, 43-52.

Kiyonaga, K., Grainger, J., Midgley, K. J., \& Holcomb, P. J. (2007). Masked cross-modal repetition priming: An event-related potential investigation. Language \& Cognitive Processes, 22, 337-376.

Knobel, M., Finkbeiner, M., \& Caramazza, A. (2008). The many places of frequency: Evidence for a novel locus of the lexical frequency effect in word production. Cognitive Neuropsychology, 25, 256-286.

Koester, D., \& Schiller, N. O. (2008). Morphological priming in overt language production: Electrophysiological evidence from Dutch. NeuroImage, 42, 1622-1630.

Kroll, J. F., Bobb, S. C., \& WodniecKa, Z. (2006). Language selectivity is the exception not the rule: Arguments against a fixed locus of language selection in bilingual speech. Bilingualism: Language \& Cognition, 9, 119-135.

Kroll, J. F., \& Stewart, E. (1994). Category interference in translation and picture naming: Evidence for asymmetric connection between bilingual memory representations. Journal of Memory \& Language, 33, 149-174.

Levelt, W. J. M., Roelofs, A., \& Meyer, A. S. (1999). A theory of lexical access in speech production. Behavioral \& Brain Sciences, 22, 1-75.

McClelland, J. L., \& Rumelhart, D. E. (1981). An interactive activation model of context effects in letter perception: I. An account of basic findings. Psychological Review, 88, 375-407.

Meuter, R. F. I., \& Allport, A. (1999). Bilingual language switching in naming: Asymmetrical costs of language selection. Journal of Memory \& Language, 40, 25-40.

Midgley, K. J., Holcomb, P. J., \& Grainger, J. (2009). Masked repetition and translation priming in second language learners: A window on the time-course of form and meaning activation using ERPs. Psychophysiology, 46, 551-565.
Petit, J.-P., Midgley, K. J., Holcomb, P. J., \& Grainger, J. (2006). On the time-course of letter perception: A masked priming ERP investigation. Psychonomic Bulletin \& Review, 13, 674-681.

Rodriguez-Fornells, A., Schmitt, B. M., Kutas, M., \& Münte, T. F. (2002). Electrophysiological estimates of the time course of semantic and phonological encoding during listening and naming. Neuropsychologia, 40, 778-787.

Rösler, F., PÜtz, P., Friederici, A., \& Hahne, A. (1993). Event-related brain potentials while encountering semantic and syntactic constraint violations. Journal of Cognitive Neuroscience, 5, 345-362.

Schmitt, B. M., Münte, T. F., \& Kutas, M. (2000). Electrophysiological estimates of the time course of semantic and phonological encoding during implicit picture naming. Psychophysiology, 37, 473-484.

SEgui, J., \& Grainger, J. (1990). Priming word recognition with orthographic neighbors: Effects of relative prime-target frequency. Journal of Experimental Psychology: Human Perception \& Performance, 16, 65-76.

Tremblay, P., Shiller, D. M., \& Gracco, V. L. (2008). On the timecourse and frequency selectivity of the EEG for different modes of response selection: Evidence from speech production and keyboard pressing. Clinical Neurophysiology, 119, 88-99.

van Turennout, M., Hagoort, P., \& Brown, C. M. (1997). Electrophysiological evidence on the time course of semantic and phonological processes in speech production. Journal of Experimental Psychology: Learning, Memory, \& Cognition, 23, 787-806.

van Heuven, W. J. B., Dijkstra, A., \& Grainger, J. (1998). Orthographic neighborhood effects in bilingual word recognition. Journal of Memory \& Language, 39, 458-483.

Verhoef, K., Roelofs, A., \& Chwilla, D. J. (2009). Role of inhibition in language switching: Evidence from event-related brain potentials in overt picture naming. Cognition, 110, 84-99.

\section{NOTE}

1. We used a 70-msec duration for primes because a pilot study failed to demonstrate any significant priming effects when primes were $50 \mathrm{msec}$ in duration.

(Manuscript received March 13, 2009; revision accepted for publication June 18, 2009.) 